\title{
ROCKET ENGINE TURBINE BLADE SURFACE PRESSURE DISTRIBUTIONS: FXPERIMENT AND COMPUTATIONS
}

\author{
Susan T. Hudson* \\ Department of Mechanical Engineering \\ Mississippi State University \\ Starkville, MS 39762 \\ Thomas F. Zoladz \\ Daniel J. Dorney ${ }^{\ddagger}$ \\ Space Transportation Directorate \\ NASA Marshall Space Flight Center \\ Huntsville, AL 35812
}

Design point experimental results only were presented previously in AIAA 2000-3239

\footnotetext{
* Assistant Professor, Senior Member AIAA

+ Aerospace Engineer

‡ Aerospace Engineer, Associate lellow AIAA
} 


\begin{abstract}
$\underline{\text { Abstract }}$
Understanding the unsteady aspects of turbine rotor flow fields is critical to successful future turbine designs. A tichnology program was conducted at NASA's Marshall Space Flight Center to increase the understanding of unsteady environments for rocket engine turbines. The experimental program involved instrumenting turbine rotor blades with miniature surfacemounted high frequency response pressure transducers. The turbine model was then tested to measure the unsteady pressures on the rotor blades. The data obtained from the experimental program is unique in two respects. First, much more unsteady data was obtained (several minutes per set point) than has been possible in the past. Also, an extensive steady performance database existed for the turbine model. This allowed an evaluation of the effect of the on-blade instrumentation on the turbine's performance. A three-dimensional unsteady Navier-Stokes analysis was also used to blindly predict the unsteady flow field in the turbine at the design operating conditions and at +15 degrees relative incidence to the first-stage rotor. The predicted time-averaged and unsteady pressure distributions show good agreement with the experimental data. This unique data set, the lessons learned for acquiring this type of data, and the improvements made to the data analysis and prediction tools are contributing significantly to current Space Launch Initiative turbine airflow test and blade surface pressure prediction efforts.
\end{abstract}

\title{
$\underline{\text { Nomenclature }}$
}

$\mathrm{C}_{0}: \quad$ Spouting Velocity (ii/s)

$\mathrm{C}_{\mathrm{p}}$ : $\quad$ Specific heat at constant pressure $\left(\mathrm{BTU} / \mathrm{lb}_{\mathrm{m}}{ }^{\circ} \mathrm{R}\right)$

FP: $\quad$ Flow parameter

$\mathrm{g}_{\mathrm{c}}$ : Conversion constant $\left(32.174\left(\mathrm{ft}^{*} \mathrm{lb}_{\mathrm{m}}\right) /\left(\mathrm{lb}_{\mathrm{f}}{ }^{*} \mathrm{~s}^{2}\right)\right)$

J: Conversion constant (778.3 ft-lbf/BTU) 
M: $\quad$ Mach number

N: $\quad$ Speed (RPM) or synchronous spectral component

P: $\quad$ Pressure (psia)

Pr: $\quad$ Pressure ratio

$\mathrm{T}: \quad$ Temperature $\left({ }^{\circ} \mathrm{R}\right)$

Tq: $\quad$ Torque $\left(\mathrm{ft}-\mathrm{lb} \mathrm{b}_{\mathrm{f}}\right)$

$\mathrm{U}: \quad$ Disk tangential speed (ft/s)

$U: \quad$ Uncertainty

$\dot{\mathrm{W}}$ : Mass flow rate $\left(\mathrm{lb}_{\mathrm{m}} / \mathrm{sec}\right)$

$\alpha: \quad$ Absolute circumferential flow angle measured from the axial direction

$\beta: \quad$ Relative circumferential flow angle measured from the axial direction

$\gamma: \quad$ Ratio of specific heats

$\eta: \quad$ Efficiency

Subscripts

n: Tota!

1: Inlet

2: $\quad$ Exit

ave: Average

Fac: Facility

max: Maximum value

min: Minimum value

inst: Instantaneous value

th: Thermodynamic method 
t-s: total-to-static

$\mathrm{t}-\mathrm{t}: \quad$ total-to-total

\section{Introduction}

The goals of future and next generation reusable launch systems are to increase safety and reliability, to reduce unit and/or operational costs (life, time between replacement and overhauls, operations complexity), and to reduce weight. To meet these goals, rocket engine components are required to be smaller, lighter weight, higher performing, more reliable, and less costly. These requirements push lurbine designs to operate beyond the limits of the past. The flow through a turbine stage has always been extremely complicated. The rotor flow field in particular is unsteady and generally three-dimensional. This flow field unsteadiness is a major factor in turbine performance and life, and, as the turbine designs become more compact and closely coupled to meet new size and weight requirements, the flow field unsteadiness increases. Therefore, understanding the unsteady aspects of the flow field is critical to the successful design of future high performanct: turbines. The fundamental understanding of the flow physics will lead to more efficient designs that could significantly reduce the unsteadiness to provide more durable, higher performing turbines to meet program goals.

A technology program was conducted at Marshall Space Flight Center (MSFC) to better understand the unsteady environments of rocket engine turbines. The program involved instrumenting the $1^{\text {st }}$ stage rotor blades of the space shuttle main engine (SSME) high-pressure fuel turbopump (HPFTP) turbine with surface-mounted high frequency response pressure transducers. The HPFTP turbine model was then tested in air in the MSFC turbine test facility (TTE) to measure the un iteady pressures on the rotor blades. In addition, a time-accurate computational fluid dynarnics (CFD) analysis was performed in a computationally efficient 
manner to predict the unste.Idy flow environment using the SSME blade surface pressure data for validation.

This article discusses the experimental program and unsteady CFD results. It describes the air test conducted in the TTE including sections describing the test facility, the test model, and both the steady and unsteady instrumentation and data acquisition equipment. Issues critical to the success of the test, such as transducer calibration and data rates, are discussed. Steady state turbine performance data is presented and compared with performance data obtained from a previous test of the model in the same configuration with no unsteady instrumentation. Blade surface pressure data is then presented to demonstrate data repeatability and validation. Next, reduced time averaged and lime resolved pressure data are discussed. Finally, the unsteady CFD methodology and results ale presented along with comparisons to the experimental data. This unique data set, the lessons learned for acquiring this type of data, and the improvements made to the data analysis and prediction tools are contributing significantly to current Space Launch Initiative turbine airflow test and blade surface pressure prediction efforts.

\section{Facility Description}

The test series was conducted in MSFC's cold air flow TTE. ' The TTE (Fig. 1) is a blowdown facility that operates by expanding high-pressure air (420 psig) from one or two-6000 cubic feet air tanks to either atmospheric or vacuum conditions. (The recent addition of an ejector system to the facility extended the facility exit condition capability to vacuum conditions.) Air flows from the storage tanks through a heater section, quiet trim control valve, and a calibrated subsonic mass flow venturi Flow then continues through the test model, backpressure valve, and exhausts to atmosphere or vacuum. The facility can accommodate axial flow, radial inflow, and radial outflow turbines. 
This equipment can deliver up to 220 psia air for run times from 30 seconds to over one hour, depending on inlet pressure and mass flow rate. The heater allows a blowdown-controlled temperature between $530^{\circ} \mathrm{R}$ and $830^{\circ} \mathrm{R}$. The facility has manual set point closed-loop control of the model inlet total pressure, inlet total temperature, shaft rotational speed, and pressure ratio. In addition to these control parameters, the facility can accurately measure mass flow rate, torque, and horsepower. The associated low-speed data acquisition system is capable of measuring 512 pressures, 120 temperatures, and several model health-monitoring variables. The high-speed data acquisition system will be discussed in a subsequent section.

\section{Model Description}

The model tested, named the HPFTP Turbine Test Article (TTA), was a full-scale model of the Rocketdyne HPFTP turbine with rough rotor blades in the baseline configuration (Fig. 2). The model had been tested previously in this configuration, and the configuration along with the performance test results are documented in reference 2. Unlike the previous testing, ${ }^{2}$ the model bullnose was modified for this test to accommodate a slip ring unit for the unsteady pressure

measurements. ${ }^{3}$ The effect of this modification on turbine performance will be addressed when the test results are presented.

\section{Instrumentation}

The TTA contained steady performance instrumentation as well as miniature pressure transducers on the blades for fluctuating pressure measurements. The steady state instrumentation served two purposes: performance evaluation and model health monitoring. This instrumentation included pressures (total and static), temperatures, flow angles, shaft speed pickups, and accelerometers. An overview of the steady state model instrumentation is given in Table 1. Reference 4 contains more details on the model instrumentation. 
Instrumented rings defined the turbine inlet and exit planes. Each of the rings accommodated a total of eight rakes and two probes with radial actuators. Each rake contained four probes (total pressure or Iemperature) at the turbine inlet and five probes (total pressure or temperature) at the turbine exit. These rakes could be manually adjusted for yaw angle. The probes used with the radial actuators were three-hole cobra probes that were calibrated to obtain yaw angle, total pressure, static pressurc, and total temperature. These cobra probes were used in the "autonulling" mode. The circunferential traverse actuators were not used on the inlet and exit rings. Both rings were "locked" in the $0^{\circ}$ position.

The model included numerous static pressure measurements along the turbine inner diameter (ID) and outer diameter (OD) flowpath walls. Static pressure instrumentation was also present on the stator vanes along the suction and pressure surfaces at $10 \%, 50 \%$, and $90 \%$ span.

The $1^{\text {st }}$ stage turbine blades were instrumented with a total of 24 semiconductor type miniature fluctuating pressure transducers manufactured by Kulite. ${ }^{3}$ The installed frequency response of the transducers was $100 \mathrm{kHz}$ and provided ample bandwidth for the experiment since the $1^{\text {st }}$ stationary vane passage frequency was approximately $4800 \mathrm{~Hz}$. Fluctuating pressure transducer footprints were approximately $0.5 \mathrm{~mm} \times 0.5 \mathrm{~mm}$ with the sensing diaphragm flush with the blade surface (Fig. 3). The sensors were distributed over seven turbine blades at various span and chord locations. Table 2 describes the sensor locations in detail.

Sensor wiring was routed down each blade across the disk to a wire carrier where a pin connection was made to a slip ring. ${ }^{3}$ A 100 channel high-speed slip ring unit (SRU) routed the sensor output to the downsiream signal conditioning and data acquisition equipment. The model was modified to accommodate the SRU and a shaft encoder. Since the model bullnose was modified to use the slip ring unit, the total pressure and total temperature rakes on the turbine inlet 
rotating ring were also modified from the previous performance testing. A spacer was used with these rakes to lift one of the sensors out of the flow; therefore, each inlet rake only had four probes radially in the flow in place of the five used on the previous test.

\section{High Frequency Data Acquisition}

Banks of remotely controlled Pacific Instrument amplifiers were used to amplify the millivolt scale outputs of the on-blade pressure signatures. The unsteady data acquisition system provided real-time display and acquisition of all on-blade pressure channels as well as the shaft position encoder channels (both once-per-revolution and 500 pulse-per-revolution signatures). The 32-channel Computer Aided Dynamic Data Monitoring and Analysis System (CADDMAS) was developed as a cooperative research effort with Vanderbilt University, Arnold Engineering and Development Center, and Marshall Space Flight Center. ${ }^{5,6}$ The CADDMAS is a parallel processor based on digital signal processors, analog/digital front-end processors, and standard personal computers. Using a parallel processing approach, the system achieves supercomputer performance in an interactive, high data-bandwidth environment.

The real-time capability of the CADDMAS to both display and acquire all of the on-blade measurements proved invaluable throughout the test series. Instantaneous waveform display aided pre-test sensor calibtations and identified errors in signal conditioning setup prior to test runs. With the system, turbine fluctuating pressures were sampled at $85 \mathrm{kHz}$ over acquisition sessions lasting on the order of minutes.

Transducer sensitivities of the installed pressure sensors were provided with delivery of the instrumented disk. To :nsure transducer calibration accuracy, complete end-to-end (i.e. from sensor diaphragm through digital representation) calibrations were performed at least twice each test day. Care had to be laken to guarantee that the instrumented blades had reached thermal 
stability during static step pressurizations before calibration voltages were obtained. A slight shift in the bias sensitivities in several of the channels over the duration of the testing was noted. Dunn and Haldeman noted similar behavior in their characterization of the SSME fuel turbine. ${ }^{7}$ The researchers attributed most of their long-term sensitivity drift to loss of protective RTV coating on the sensor diaphragms. The MSFC turbine model sensors utilized a similar RTV protection layer. Future blade surface pressure mapping efforts will utilize a novel temperature compensation technique to reduce surface mount pressure sensor error. ${ }^{8}$ An order of magnitude reduction in temperature induced error is expected through use of the "sense-resistor based" compensation technique.

\section{$\underline{\text { Test Conditions }}$}

Testing was conducted at a total of 17 set points. First, the turbine's aerodynamic design point from the previous performance test was repeated. ${ }^{2}$ This set point is referred to as the "old design point" (ODP) or baseline. It corresponds to the SSME 104\% rated power level (RPL) based on the Rocketdyne 'ngine power balance model of the late 1980's. Second, the turbine conditions were set to match the operating condition in reference 7 . This set point is referred to as the "Calspan set point" (CSP). Two sets of off-design conditions were then run. First, the turbine was set to $65,70,81), 90,100,104$, and $109 \%$ RPL based on the updated 1997 version of the Rocketdyne engine power balance model. Then, the turbine was run over a range of conditions to change the incidence angle on the $1^{\text {st }}$ stage rotor blades. Incidence angle set points included $0, \pm 5, \pm 15$, and \pm 25 degrees. Finally, a high turbine pressure ratio set point was run. The set point parameters $\left.f_{(}\right)^{\circ}$ the test were the turbine inlet total pressure, inlet total temperature, speed, and pressure ratio. Table 3 provides a summary of test set point parameters of interest. 


\section{Test Results and Discussion}

\section{Steady State Performance Results}

Table 4 gives a summary of the steady test results for the old design point (ODP) and the Calspan set point (CSP). Data from three test runs done at different times during testing were combined to obtain the final numbers for each set point for the current test. Each test run consisted of 10 frames of steady data. A sufficient time interval was allowed between each frame of data so that the frames could be considered independent results. The inlet and exit total pressures and temperatures given in the table are averages of the rake measurements. The turbine inlet and exit static pressures are averages of the inner and outer diameter wall static pressure measurements at these planes.

The turbine's velocity ratio, flow parameter, and efficiency are given in Table 4 to define the overall performance. $T, r$ achieve the proper units, the velocity ratio equation was

$$
\frac{U}{C_{0}}=\frac{\frac{10.069 * N}{229.18}}{\sqrt{2 g_{c} J C_{p} T_{01}\left[1-\left(\frac{P_{02}}{P_{01}}\right)^{\frac{\gamma-1}{\gamma}}\right]}}
$$

The turbine flow parameter was defined as follows:

$$
F P=\frac{\dot{W} \sqrt{T_{01}}}{P_{01}}
$$

Note that this is an "enginecring" definition for flow parameter that is not truly nondimensional.

The thermodynamic method of determining turbine efficiency was used. ${ }^{9.10}$ The temperature drop across the turbine was measured to determine the actual enthalpy change. For 
this "cold" turbine testing where the temperature was relatively low, an ideal gas was assumed and $\gamma$ and $\mathrm{C}_{\mathrm{p}}$ were considered constant.

$$
\eta_{t h}=\frac{T_{01}-T_{02}}{T_{01}\left[1-\left(\frac{P_{02}}{P_{01}}\right)^{\frac{\gamma-1}{\gamma}}\right]}
$$

Turbine steady-statt ${ }^{2}$ performance across both design and off-design conditions is shown in Fig. 4. This figure shows the thermodynamic turbine efficiency versus velocity ratio.

A detailed posttest uncertainty analysis was completed for the current test using the methodology in reference 11 . Estimates for the systematic and random components of the uncertainties of the measured variables are given in Table 5. The random component estimates were obtained directly from multiple test results based on a large sample assumption, and they include set point repeatability.

Data at the old design point test condition was compared to data obtained from previous testing to evaluate the effecl of the unsteady instrumentation on the turbine's performance. Static pressure drops through the ?urbine as well as overall performance parameters were studied.

Figure 5 gives the slatic pressure drops through the turbine for both the current test and the previous test. ${ }^{2}$ The $y$-axis in Fig. 5 is the average of the inner and outer wall static pressure measurements at each plane normalized by the static pressure at the turbine inlet. The $x$-axis represents each axial station: 1 is the turbine inlet, 2 is the $1^{\text {st }}$ stator inlet, 3 is the $1^{\text {st }}$ stator exit, 4 is the $2^{\text {nd }}$ stator inlet, 5 is the $2^{\text {nd }}$ stator exit, 6 is the turbine exit, 7 is the EGV inlet, and 8 is the EGV exit. Figure 5 shows that there was no measurable difference in the static pressure drop through the turbine between the current and previous tests. 
To compare overall performance, several parameters were studied. These parameters included facility set points as well as calculated performance parameters. The facility set points were $P_{01}, T_{01}, N$, and $\operatorname{Pr}$; therefore, velocity ratio was a set point. The calculated performance parameters that were used to compare the two data sets included the flow parameter and thermodynamic efficiency. The data from both the current test and the previous test is given in Table 4. Estimates for the random component of the uncertainty of the calculated values are given in Table 6 for the current test. The random component estimates were obtained directly from multiple test results based on a large sample assumption, and they include set point repeatability. Values for the previous test were similar.

Table 4 shows that the pressure ratios and the velocity ratios were the same for both tests. The flow parameter increased by $2.4 \%$ for the current test. The subsonic venturi used to measure the mass flow rate in the TTE was recalibrated between tests. The application of the new calibration data caused a shift in the measured mass flow rate and the corresponding flow parameter.

Thermodynamic turbine efficiency was compared between the two tests. The calculated thermodynamic efficiency was $85.7 \%$ for the previous test and $85.3 \%$ for the current test. This gives $\Delta \eta=0.4 \%$. The methodology in reference 12 was used to evaluate the difference in efficiency obtained from the two tests. The temperature measurements for both tests were made with the same thermocouples, wiring, hook-up, and data acquisition system. Similarly, the pressure measurements were made with the same instruments. hook-up, and data acquisition system. No factors were identified to change the systematic uncertainties of the measurements used to calculate the thermodynamic efficiency between the two tests. The random component of the uncertainty in the thermodynamic efficiency, including test-to-test variations, was 0.0014 or 
$0.14 \%$. Therefore, the uncertainty in the difference in efficiency between the two tests was calculated to be 0.004 or $0.4 \% .^{12}$ Since $\Delta \eta \pm U_{\Delta \eta}$ includes 0 , the difference is insignificant. ${ }^{12}$

In summary, the dala comparison showed no significant changes in turbine performance between the two tests. This leads to the conclusion that the installation of the unsteady instrumentation and the modification to the model bullnose did not have a measurable effect on the turbine's performance.

\section{Unsteady Performance Results}

Several of the turbine blade surface mounted pressures failed prior to the start of testing. Of the original 24 transduccrs, only 18 were operational for the first instrumented rotor test with three more lost during testing. In interpreting the high frequency turbine blade surface pressure data, both standard power spectral density (PSD) and synchronous time averaging (STA) processing were employed. ${ }^{13,14.15 .16}$ The high-speed data sample rate across all testing was set at $85334 \mathrm{~Hz}$ which was sufficient to capture the sixth harmonic of the $1^{\text {st }}$ stationary vane passing component. The PSD block size for the data archival was set to 8192 yielding a resolution handwidth of $10.4 \mathrm{~Hz}$, or approximately $0.23 \%$ of the $1^{\text {st }}$ vane nassing rate at baseline set point conditions. A slight periorlic rotor speed variation (measured in revolutions per minute, RPM) was noted in testing, but did not affect the blade surface pressure characterization effort. Figure 6 displays the periodic variation in frequency of the $1^{\text {st }}$ vane passing rate as well as its first harmonic for the baseline set point at 6982 RPM. The variation was approximately 18-RPM peak-to-peak at $0.19 \mathrm{~Hz}$. STA processing provided pressure waveforms free of random and nonsynchronous disturbances. The STA process utilizes a trigger-pulse (supplied by the shaft key phaser) to synchronize the averaging process with shaft rotation. The resulting waveform over one full revolution contains information that is purely synchronous related. The signal 
analysis technique is equivalent to a comb filter with center frequencies at the synchronous rate and subsequent harmonics. Both the maximum peak-to-peak variation and mean of these pressure waveforms were used as primary blade surface pressure assessment attributes.

All displayed unstiady results have been normalized by model inlet total pressure. Negative chord values denıte pressure surface placement while positive denote suction surface. In terms of percentages, the leading edge of the turbine blade corresponds to a $0 \%$ chord, while $100 \%$ chord denotes trailing edge. Averaging frame length for all unsteady parameters was 25 seconds, which guarantied at least 980 shaft revolutions per estimate at the lowest test set point speed of 2344 RPM.

A sliding-average process was applied to STA waveforms to eliminate what appeared to be slip-ring related noise. The first equivalent low-pass filter zero-crossing for the averaging was approximately $195 \mathrm{~N}$. With a $1^{\text {st }}$ stage vane rotor count of 41 , the pass band contained the first three harmonics of $1^{\text {st }}$ stationary vane passing.

Figure 7 shows the normalized average surface pressure distribution along the chord at blade mid-span for baseline conditions. The variation across test repeats reflects sensor bias drifting which could not be: removed from the acquired data. Implementation of the calibration method of Ainsworth ${ }^{8}$ is expected to significantly improve the thermally driven uncertainty in future turbine blade pressure mapping efforts. Figure 8 shows the normalized maximum peak-peak variation (or unsteady envelope) of surface pressures also at mid-span across chord for the baseline condition. The unsteady envelope was very repeatable across the baseline runs as shown across pressure locaitions.

Figure 9 displays the chordwise unsteady pressure distribution for 50\% span across 1997 SSME Power Balance Rated Power Levels (RPLs); i.e., from 65\% to 109\% RPL. Interestingly, 
the fluctuating pressure variation across power level is only slightly greater than the test-to-test variation recorded at the baseline set point (Figure 8). This suggests minimal high-speed fuel turbine blade load variation across the SSME flight envelope. Figure 10 shows the $50 \%$ span normalized unsteady pressure distribution across incidence variation from -25 degrees to +25 degrees. Peak leading edge fluctuating pressures for the entire experimental series occurred at the +25 degree incidence condition.

Detailed time-resolved pressure waveforms will be shown and discussed in the comparison of experimental data to CFD prediction.

\section{Unsteady CFD}

\section{Computational Procedur:}

The computational tool used to simulate the flow in the turbine is known as CORSAIR. The governing equations solved in CORSAIR are the time dependent, three-dimensional Reynolds-averaged Navier-Stokes equations. The algorithm used in the computational procedure consists of a time-marching, implicit, finite-difference scheme. The procedure is third-order spatially accurate and second-order temporally accurate. The inviscid fluxes are discretized according to the upwind scheme developed by Roe. ${ }^{17}$ The viscous fluxes are calculated using standard central difference;. An approximate-factorization technique was used to compute the time rate changes in the conserved variables. The turbulent viscosity is calculated using a highly modified two-layer Baldwın-Lomax algebraic turbulence model. The numerical analysis uses Message Passing Interface (MPI) and OpenMP to reduce the computation time for large-scale three-dimensional simulations.

The Navier-Stokes : 1 nalysis uses $\mathrm{O}$ - and H-type zonal grids to discretize the flow field and facilitate relative motion of the rotating components. The O-grids are body-fitted to the surfaces 
of the airfoils and generatid using an elliptic equation solution procedure. They are used to properly resolve the viscous flow in the blade passages and to easily apply the algebraic turbulence model. The algebraically generated H-grids are used to discretize the remainder of the flow field. Figure 11 show: the computational grid at mid-span for the SSME geometry.

\section{$\underline{\text { Boundary Conditions }}$}

For subsonic inlet flow, the total pressure, total temperature, and the circumferential and radial flow angles are specilied as a function of the radius. The upstream-propagating Riemann invariant is extrapolated from the interior of the computational domain.

For subsonic outflow the circumferential and radial flow angles, total pressure, and the total temperature are extrapolated from the interior of the computational domain. The ratio of the exit static pressure to the inlet total pressure is specified at mid-span of the computational exit, and the pressure at all other radial locations at the exit is obtained by integrating the equation for radial equilibrium. Periodicity is enforced along the outer boundaries of the H-grids in the circumferential direction.

No-slip boundary conditions are enforced along the solid surfaces. It was assumed that the normal derivative of the pressure was zero at solid wall surfaces. All solid surfaces were also assumed to be adiabatic. 'The flow variables at zonal boundaries were explicitly updated each time step by interpolating values from the adjacent grids.

\section{Geometry, Grids, and Simulation Characteristics}

The two-stage turbine geometry contained 41 first-stage vanes, 63 first-stage rotors, 39 second-stage vanes, and 59 second-stage rotors. A 40-60-40-60 blade count approximation was made allowing 2-3-2-3 simulations. To keep the pitch-to-chord ratio constant, the first-stage vane airfoils were scaled by factor of $41 / 40$, the first-stage rotor blades were scaled by a factor of 
$63 / 60$, the second-stage vanc airfoils were scaled by a factor or $39 / 40$, and the second-stage rotor blades were scaled by a factor of $59 / 60$. The rotor tip clearances were set to $1.4 \%$ of the rotor height. A total of 3,556,785 grid points were used. The average value of $\mathrm{y}^{+}$, the nondimensional distance of the first grid point above the wall, was approximately 1.5 for the airfoil surfaces and 3.5 for the endwalls.

The simulations were performed on $20400-\mathrm{MHz}$ processors of an Origin2000 located at NASA Ames Research Center. The 20 processors consisted of 10 MPI processes and two OpenMP threads per MPI process. The simulations were run for 10 characteristics cycles, where a characteristic cycle consists of three rotor blades passing by two vane airfoils. The simulations were performed at 12,000 iterations per cycle and required approximately $3 \times 10^{-6} \mathrm{sec} / \mathrm{grid}$ point/iteration computation time.

\section{$\underline{\text { Results }}$}

The predicted time-averaged flow values and performance parameters for the "baseline set point" equivalent turbine inlet conditions are presented in Table 7 . The flow values were normally recorded midway between blade rows, except for the first row where the values were recorded at the computational inlet (approximately one axial chord upstream of the first-stage vane leading edge) and the last row where the values were recorded at the computational exit (approximately one axial chord downstream of the second-stage rotor trailing edge). The overall total-to-total efficiency of the turbine was 0.888 based on the change in the total temperature and 0.870 based on the change in circumferential velocity. The overall total-to-static efficiency of the turbine was 0.843 .

Instantaneous entropy contours at the mid-span section of the turbine for the design operating conditions are shown in Fig. 12. Entropy contours are useful in highlighting the 
convection of airfoil wakes and regions of high loss. Figure 12 clearly shows the stretching of the vane wakes as they pass through the downstream rotors. The stretching of the wakes is caused by the differences $: 1 n$ the core velocities on the pressure and suction sides of the rotor passages. The airfoil wakes can persist through several blade rows, leading to an accumulation of wakes in the downstream rows. In a subsonic turbine, such as the one under consideration in this study, the airfoil wakes tend to drive the dominant unsteady frequencies in adjacent blade rows. The accumulation of wakes in the downstream rows can also lead to the presence of unsteadiness at harmonics of the fundamental frequencies.

\section{Comparisons with Experiment}

For steady state turhine performance, CFD predicted an overall total-to-total efficiency of 0.888 for the baseline set point. The corresponding experimentally derived efficiency for the current test (Table 4) was ( 853 . It is not unusual for CFD simulations to yield a higher overall efficiency; the CFD model does not contain all the loss mechanisms present in the experimental apparatus. The CFD modeI includes only the viscous losses due to the airfoil boundary layers, the endwall boundary layers (and associated secondary flows), and the tip clearance flows.

Figure 13 contains predicted versus experimental normalized time-averaged surface pressure distributions (bascline set point) at $50 \%$ span of the first-stage rotor while Figure 14 contains the unsteady distributions. All values have been normalized by inlet total pressure. The CFD results exhibit good igreement with both the experimental time-averaged values and the amplitude of the unsteadiness.

Figures 15 and 16 compare the instantaneous pressure waveforms for arbitrary pressure and suction surface locations on the first-stage rotor, respectively. Instantaneous pressure is plotted versus rotation index where an index of 0.1 represents $10 \%$ of a shaft revolution. In 
developing the overlays, the experimental and computed waveforms were arbitrarily aligned to match phase. As can bc seen in the comparisons, the CFD prediction not only matches fluctuating pressure amplitude, but it also predicts the shape of the waveform reasonably well. Both the experimental and predicted results indicate that the predominant unsteadiness is associated with the periodic passing (as seen from the rotor) of the upstream vane wakes. The amplitude of the unsteadiness is greater on the suction surface of the rotor due to its increased exposure to the vane wakes and potential field.

In addition to the baseline set point, a CFD simulation was also performed for an off-design turbine condition corresponding to +15 degrees incidence on the first-stage rotor. Figure 17 contains the predicted and experimental normalized time-averaged surface pressure distributions at $50 \%$ span, and Figure 18 contains the corresponding unsteady pressure envelopes. While the predicted time-averaged surface pressure distribution compares well with the experimental data, the suction-side leading edge unsteady distributions exhibit some discrepancies. In particular, the predicted suction side distribution is shifted more towards the leading edge than is indicated by the experimental data. The main sources of these discrepancies are (1) The experiments were performed with rough blade surfaces while the CFD simulations assumed smooth blades. This difference has no effect on the set point results but does affect the incidence angle at which the suction surface boundary layer will begin to separate. (2) The turbulence model in the CFD code, although well anchored for turbomachinery simulations, will begin to break down at far off-design flow conditions.

Figures 19 and 20 compare the instantaneous pressure waveforms for the same arbitrary pressure and suction surface locations shown for the baseline configuration. The predicted pressure surface trace displays excellent agreement with the experimental data. Both the 
predicted results and experimental data indicate that the predominant unsteadiness is associated the vane-passing frequency. The experimental trace on the suction surface shows the predominant unsteadiness accurs at the vane-passing frequency, while the predicted results also contain higher-frequency content. This additional frequency content is consistent with intermittent breakdown of the suction-surface boundary layer in the simulations due to the assumption of smooth blades and limitations of the turbulence model.

\section{Summary and Conclusions}

A technology program to increase the understanding of unsteady environments for rocket engine turbines was successfully completed. Steady measurements used to evaluate turbine performance as well as unsteady pressure measurements on the turbine rotor blades were obtained.

The steady measurements were used to define the turbine's performance at each set point. Additionally, the existence of a comprehensive steady data set on the turbine tested allowed a unique opportunity to evaluate the effect of the installation of the unsteady instrumentation on the turbine's performance. Data comparisons between the current test and a previous test of the same configuration with no unsteady instrumentation showed that the unsteady instrumentation and resulting hardware mollifications did not affect the performance of the turbine. This data also demonstrated excellen facility repeatability, both run-to-run and test-to-test.

With the unsteady clata, success in the acquisition and evaluation of complex high-speed turbine on-blade surface pressure environments was shown. The benefit of advanced high-speed digital signal acquisition and processing was demonstrated in the accurate mapping of the blade unsteady pressures. The time-averaged and unsteady CFD results showed very good agreement with the experimental data at the design operating conditions and fair-to-good agreement at an 
operating condition corresponding to +15 degrees of incidence on the first-stage rotor. The high-fidelity flow features, characterized in the successful effort will undoubtedly aid the advancement of CFD prediction tools. Lessons learned will be invaluable in the planning and implementation of similar blade mapping efforts for advanced turbines for the next generation and future generation reusable launch systems.

\section{Acknowledgements}

The authors would like to thank the many MSFC personnel who contributed to the success of the test. Also, the work of Bill Neighbors, formerly of MSFC, and Dr. Ted Bapty, of Vanderbilt University, in drveloping the unsteady data acquisition systems is much appreciated.

\section{References}

${ }^{1}$ Bordelon, W.J. Jr. Kauffman, W.J. Jr., and Heaman, J.P., "The Marshall Space Flight Center Turbine Test Equipnıent; Description and Performance," ASME 93-GT-380, 1993.

${ }^{2}$ Hudson, S.T., Gaddis, S.W., Johnson, P.D., and Boynton, J.L., "Cold Flow Testing of the Space Shuttle Main Engine I Iigh Pressure Fuel Turbine Model," AIAA 91-2503, 1991.

${ }^{3}$ Hudson, S.T., "Space Shuttle Main Engine High Pressure Fuel Turbine Blade Pressures (TTE0009) Pretest Report," NASA/MSFC Memo ED34-01-93, April 8, 1993.

${ }^{4}$ Bordelon, W.J. Jr., "Space Shuttle Main Engine High Pressure Fuel Turbopump Turbine Test Article Phase IA Pretesı Report," NASA/MSFC Memo ED33-51-90, July 5, 1990.

${ }^{5}$ Bapty, T.A., "Model-Based Synthesis of Parallel Real-Time Systems," Ph.D. Dissertation, Vanderbilt University, December 1995.

${ }^{6}$ Abbott, B.A. and Bapty, T.A., "Experiences Using Model-Based Techniques for the Development of a Large Parallel Instrumentation System," Proc. Conf. Signal Processing Applications and Technolo:y, Cambridge, MA, pp. 573-582, 1992. 
${ }^{7}$ Dunn, M.G. and Haldeman, C.W., "Summary of Time-Averaged and Phase-Resolved Pressure and Heat Flux Me:ısurements on the First Stage Vane and Blade of the SSME Fuel-Side Turbine," NASA Earth to Orbit Conference, pp 516-524, 1994.

${ }^{8}$ Ainsworth. R.W., Miller, R.J., Moss, R.W., and Thorpe, S.J., "Unsteady Pressure and Measurement," Journal of Measurement Science and Technology, Volume 11, No. 7, July 2000.

${ }^{9}$ Rodi, F., Varetti, M., and Tomat, R., "Low Pressure Turbine Testing," AGARD-CP-293, Presented at the $56^{\text {th }}$ Symposium of the AGARD Propulsion and Energetics Panel, Turin, Italy, September 29-October 3, 1980.

${ }^{10}$ Hudson, S.T. and Coleman, H.W., "Analytical and Experimental Assessment of Two Methods of Determining Turbine Efficiency," Journal of Propulsion and Power, Vol. 16, No. 5, September-October 2000.

${ }^{11}$ Coleman, H.W. and Steele, W.G., Experimentation and Uncertainty Analysis for Engineers, $2^{\text {nd }}$ Edition, Wiley, New York, 1999.

${ }^{12}$ Kammeyer, M.E. and Rueger, M.L., "On the Classification of Errors: Systematic, Random, and Replication Level," AIAA 2000-2203, 2000.

${ }^{13}$ Bendat, J. S. and Piersol, A. G., Engineering Applications of Correlation and Spectral Analysis, Wiley and Sons, New York, 1980.

${ }^{14}$ McFadden, P.D. "Interpolation Techniques for the Time Domain Averaging of Vibration Data With Application to Helicopter Gearbox Monitoring," Aero Propulsion Technical Memorandum 437, AR-004-488, Dept. of Defense-Science and Technology Org. Aeronautical Research Lab., Commonwealth of Australia, 1986.

${ }^{15}$ Braun, S. and Datner, B., "Analysis of roller/ball Bearing Vibrations," ASME paper No. 77-WA/DE-5, 1977. 
${ }^{16}$ Leon, R.L. and Dowling, M.J., “On-line Monitoring of Turbine Blades for Incipient Failure Detection," EPRI Final Report RP1854-1,2, 1986.

${ }^{17}$ Roe, P.L, "Approximate Riemann Solvers, Parameter Vectors, and Difference Schemes," Journal of Computational Physics, Vol. 43, 1981, pp. 357-372. 


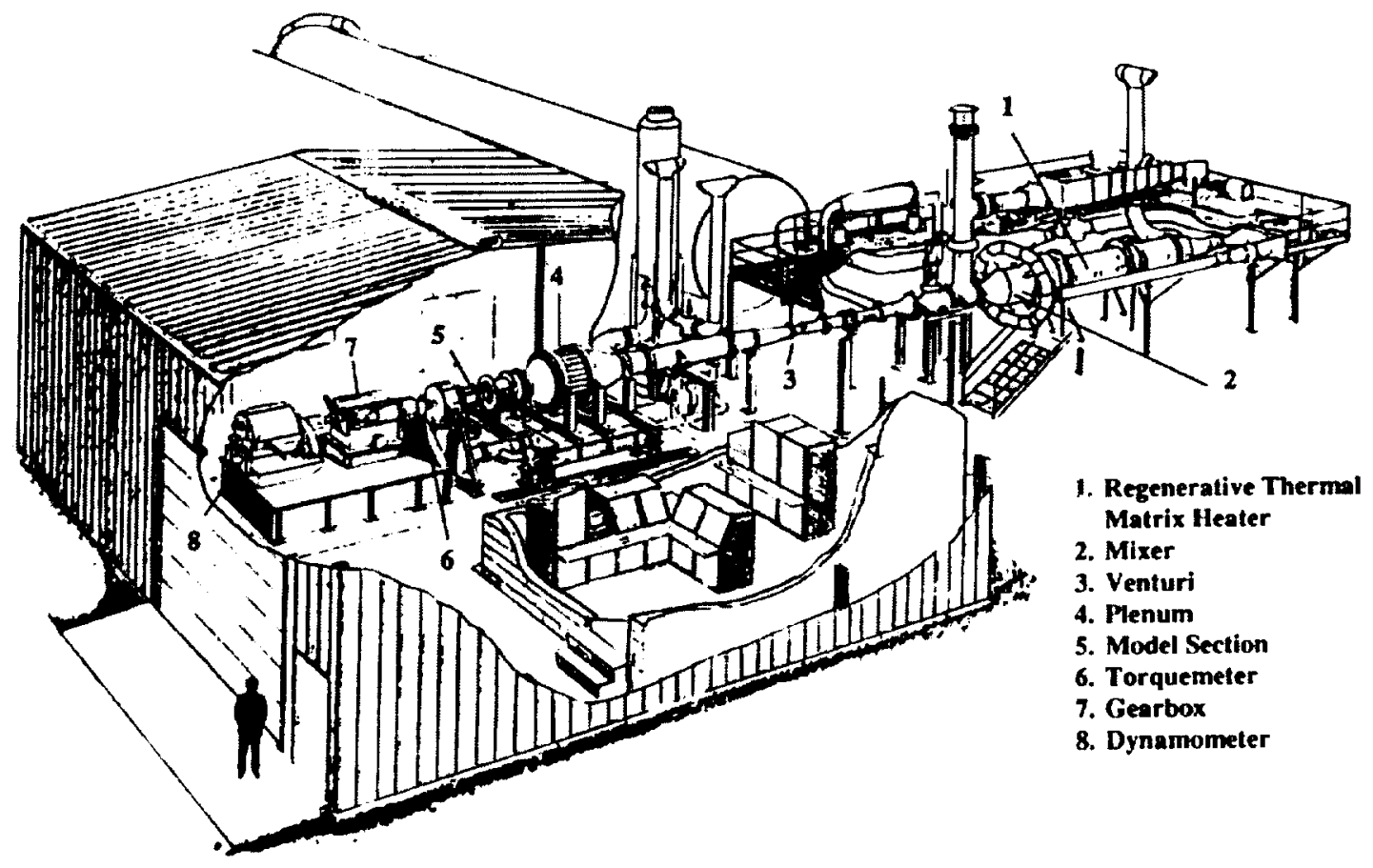

Fig. 1. Schematic of TTE 


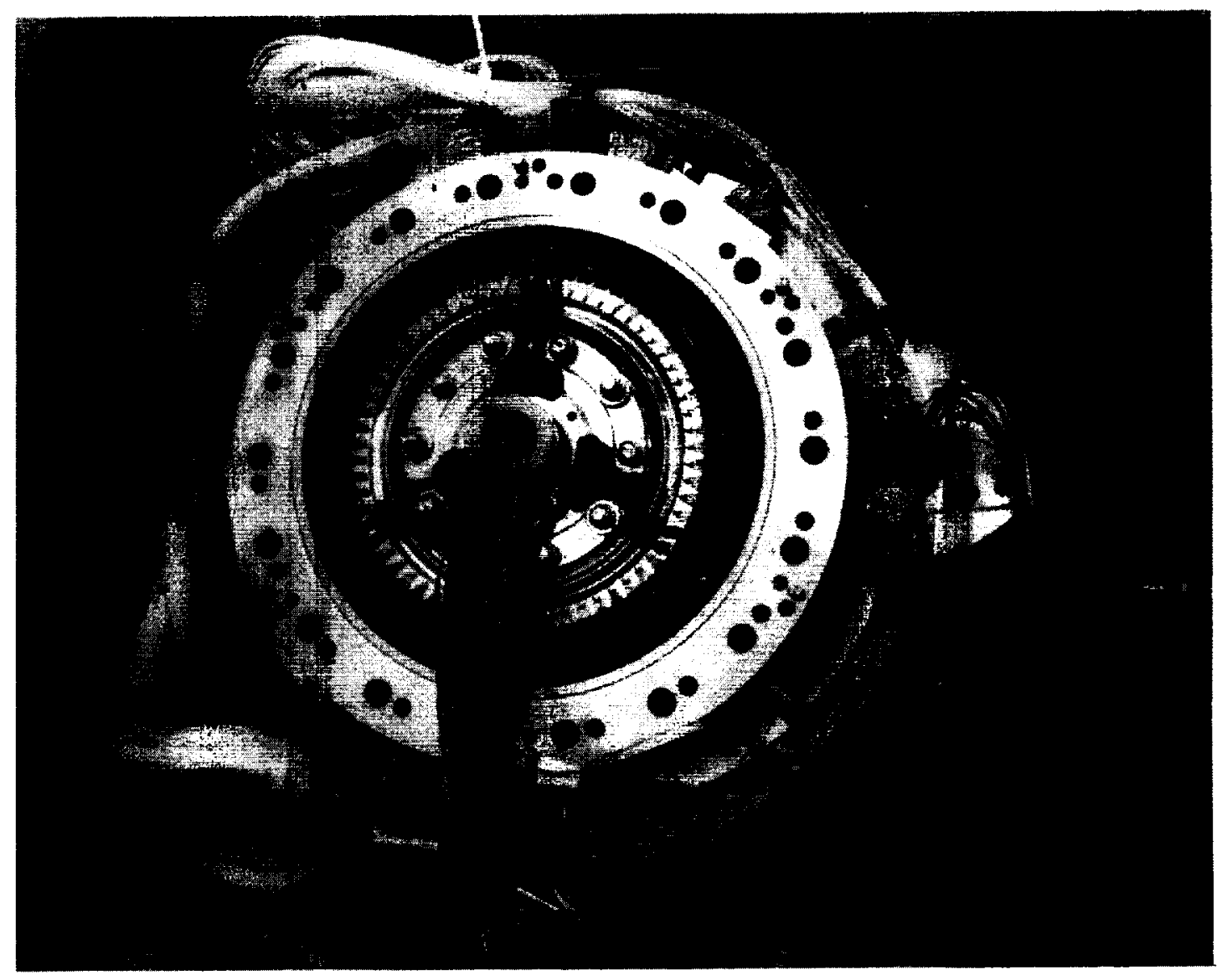

Fig. 2. Turbine Test Article 


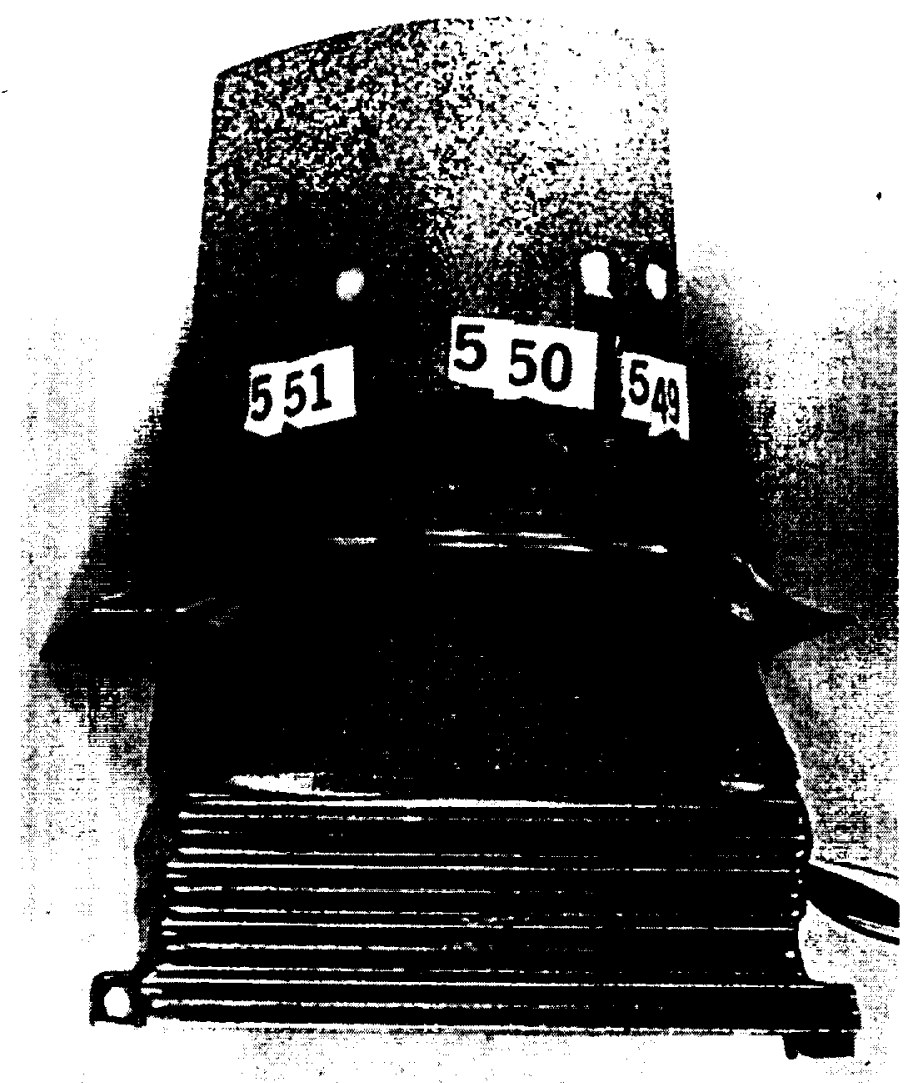

Fig. 3. Instrumented Blade (50\% Span Suction Side) 


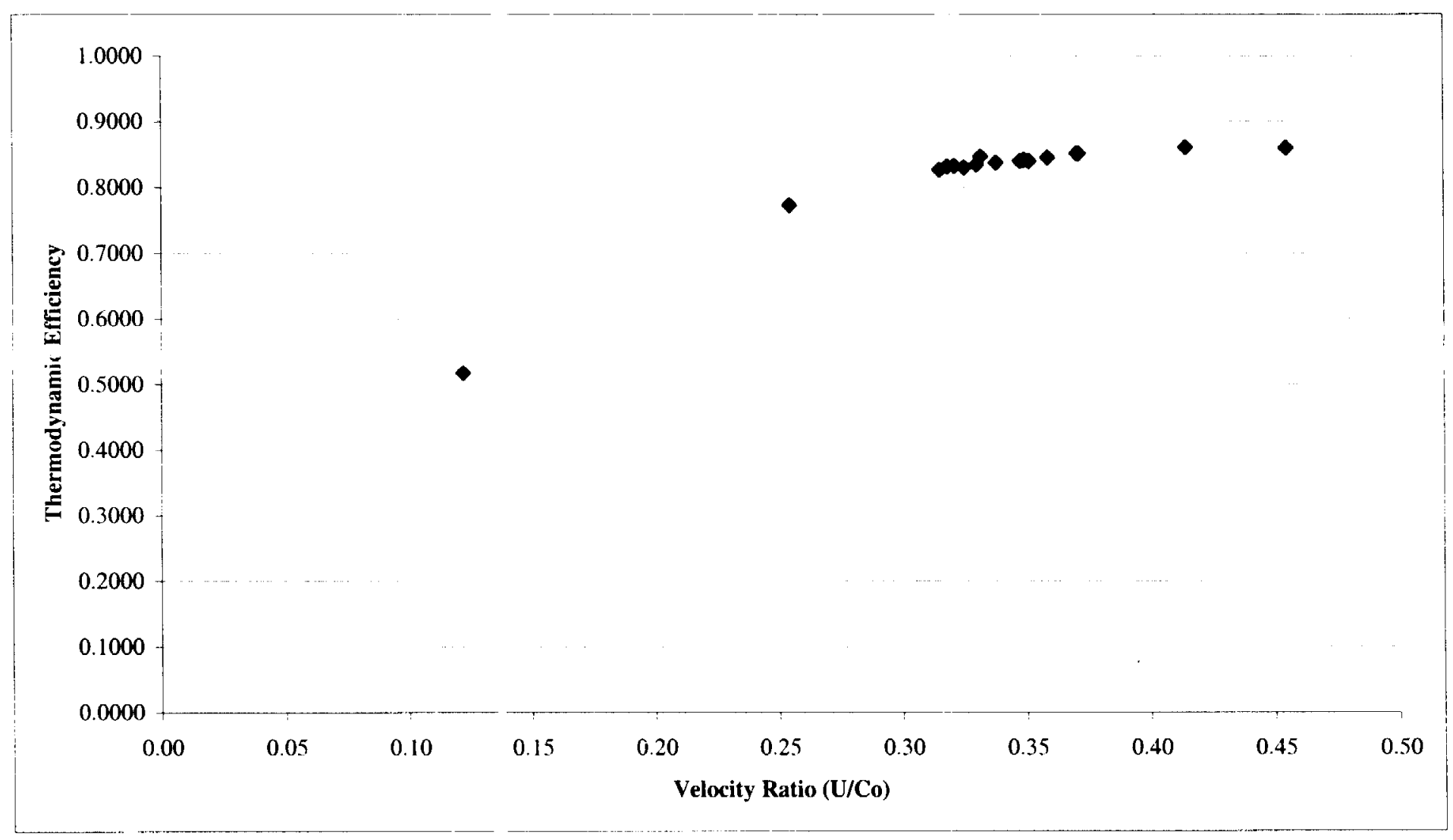

Fig. 4. Thermodynamic Efficiency vs. Velocity Ratio 


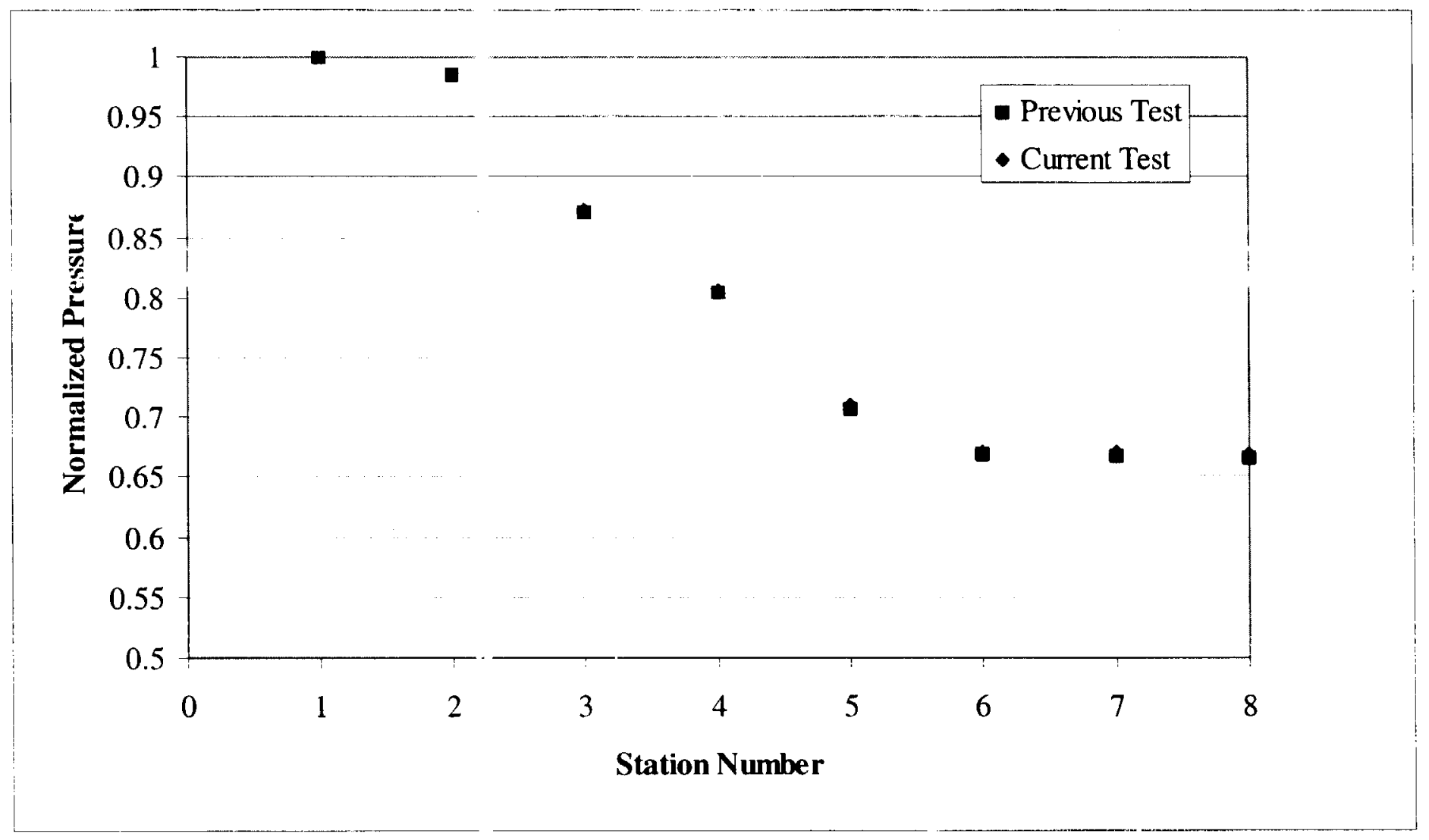

Fig. 5. Normalized Static Pressure Drop Through Turbine 


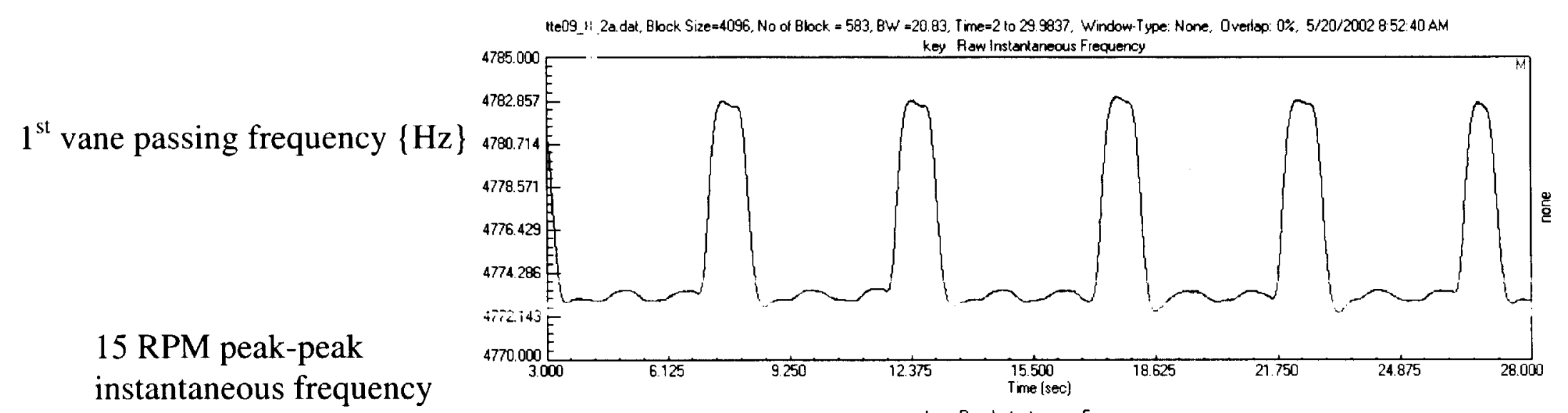
instantaneous frequency variation at $0.19 \mathrm{~Hz}$

$1^{\text {st }}$ harmonic of vane passing frequency $\{\mathrm{Hz}\}$

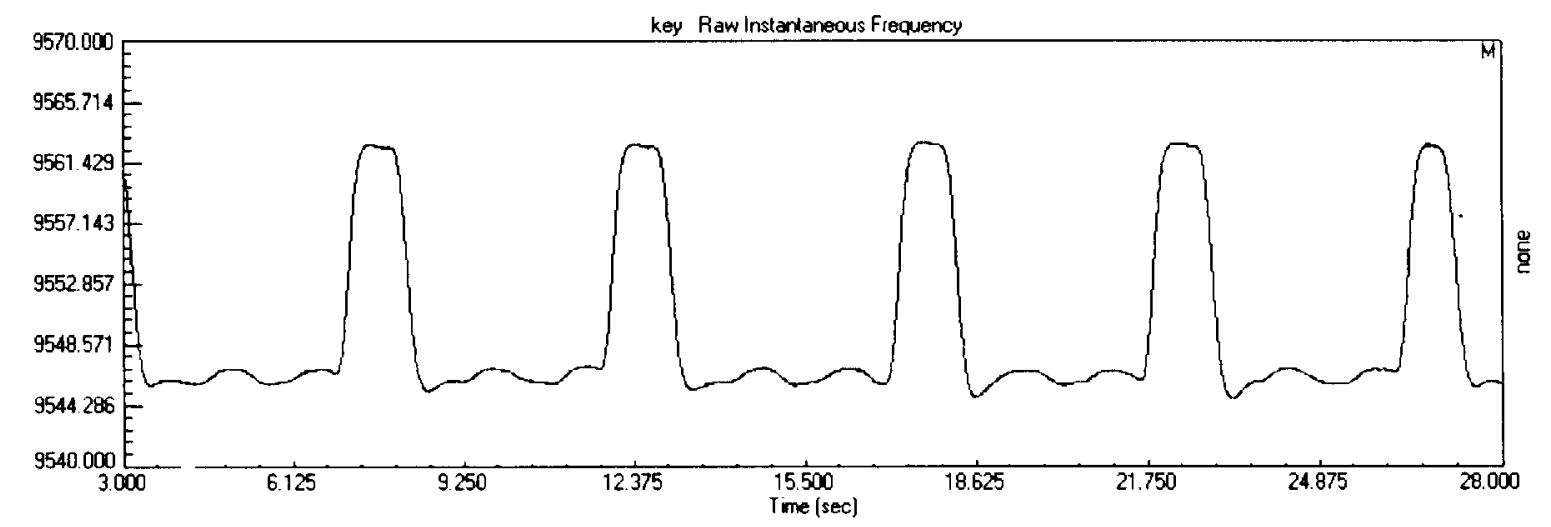

Fig. 6. Shaft Speed Variation 


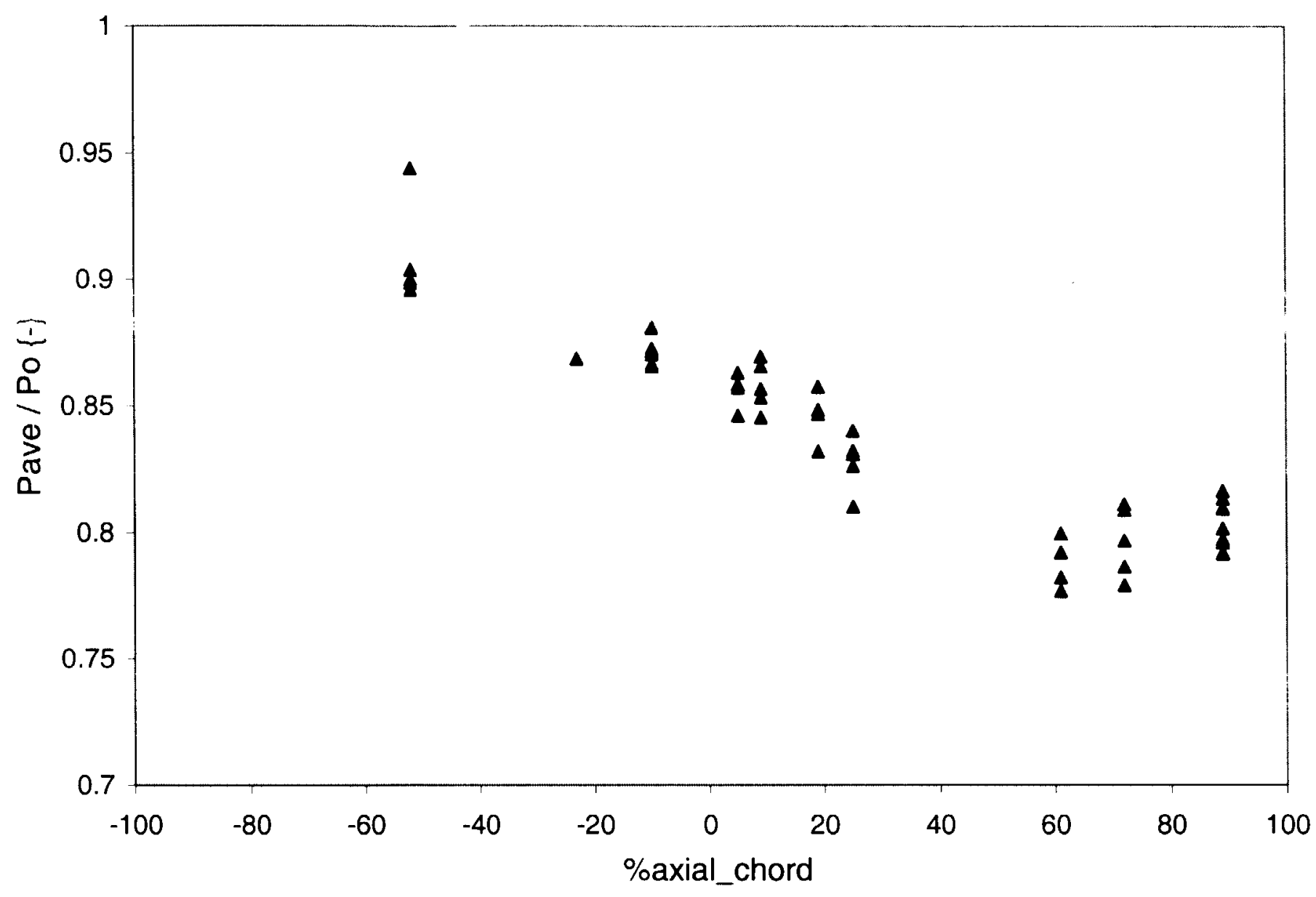

Fig. 7. Average Surface Pressure Distribution at 50\% Span for Baseline Conditions 


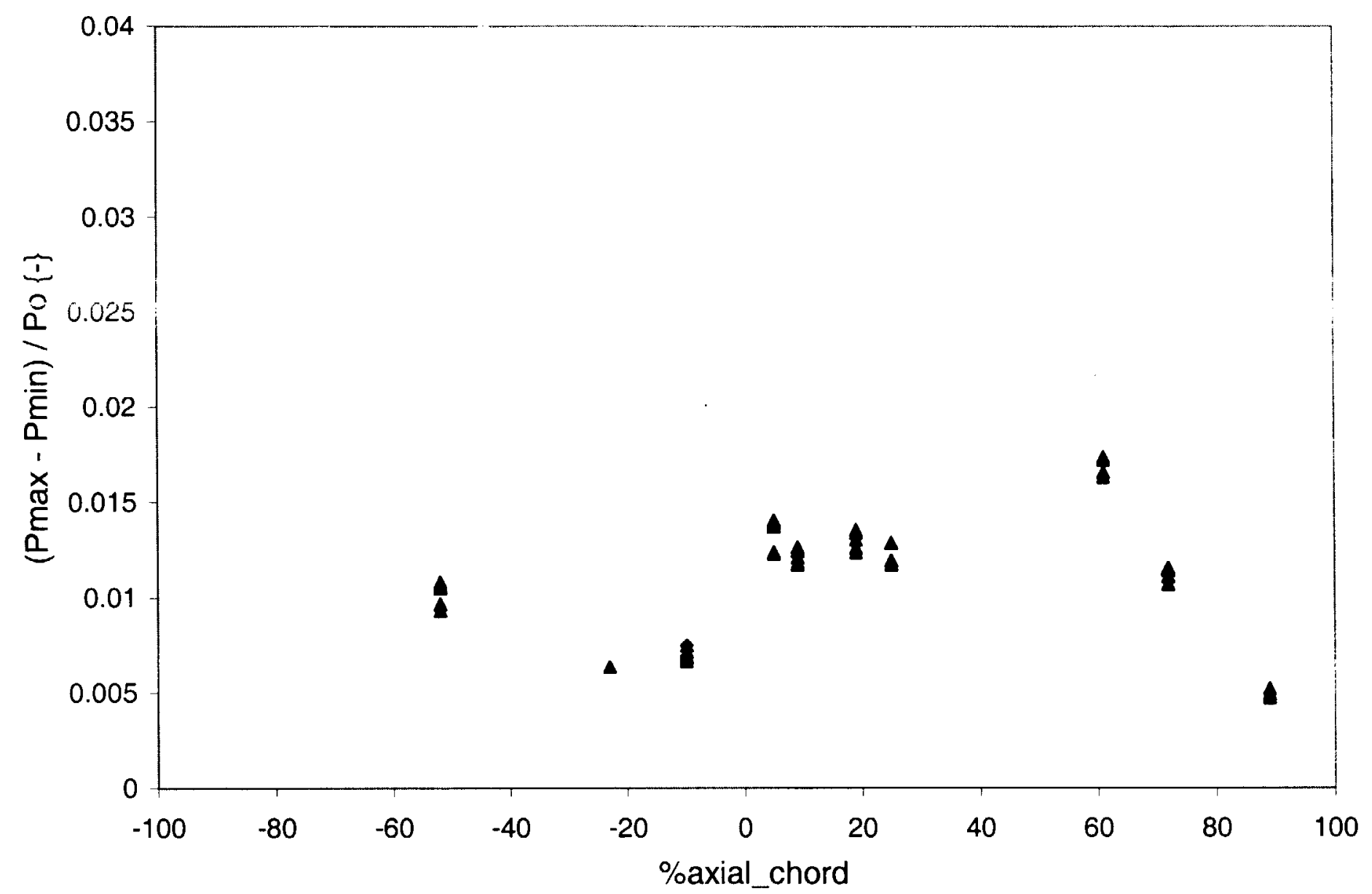

Fig. 8. Unsteady Surface Pressure Envelope at 50\% Span for Baseline Conditions 


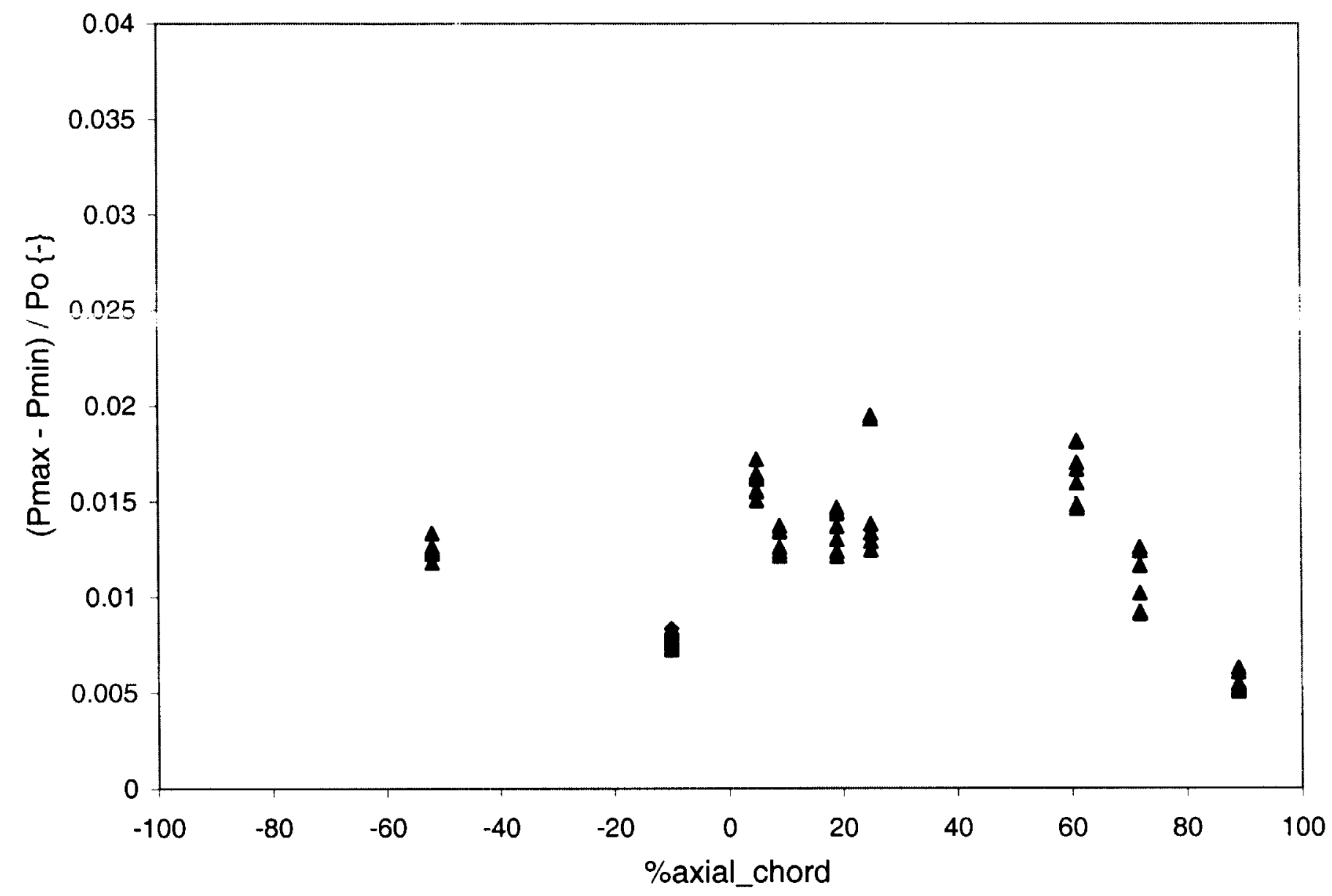

Fig.9. Unsteady Surface Pressure Envelope at 50\% Span Across 1997 SSME Power Balance Rated Power Levels 


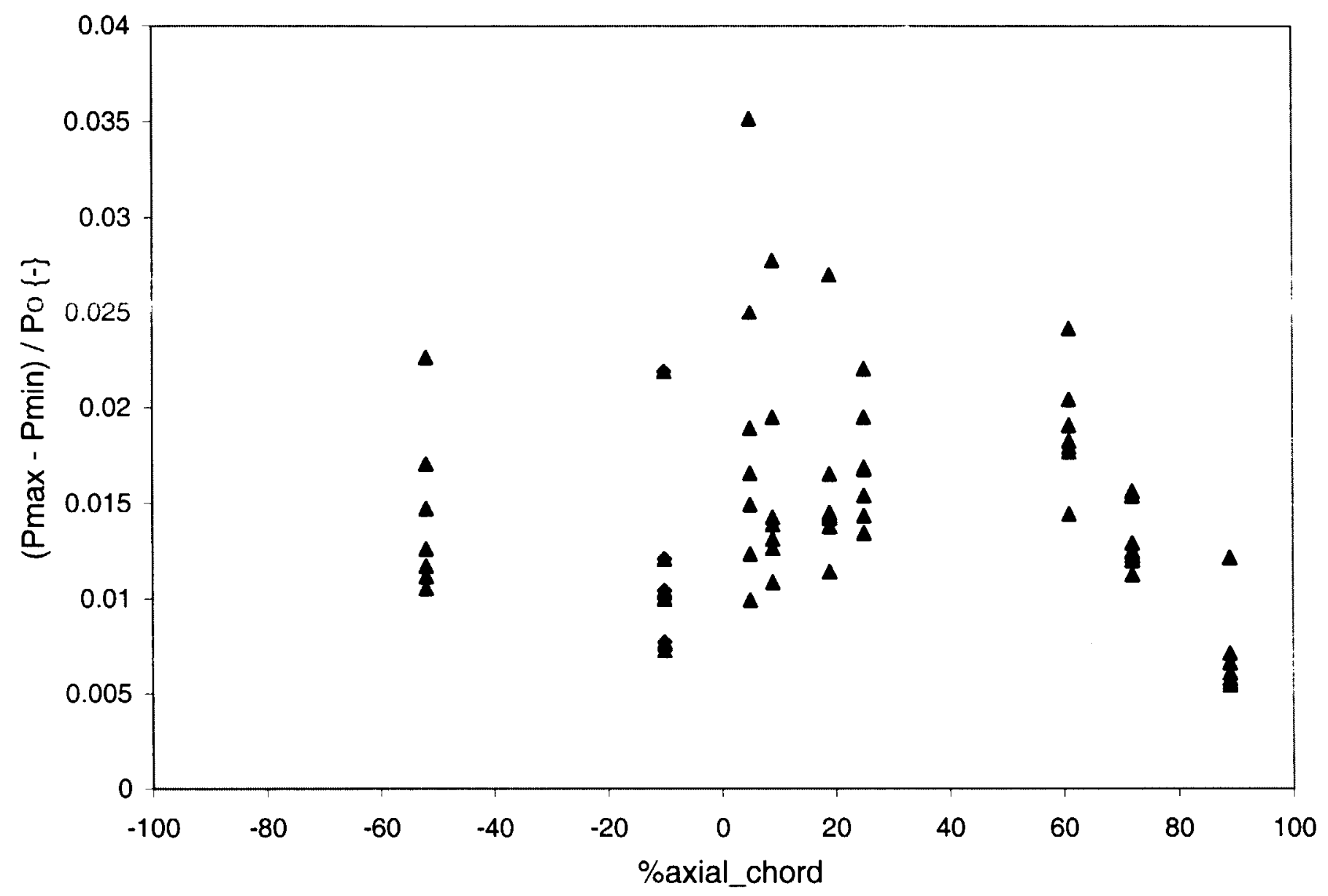

Fig. 10. Unsteady Surface Pressure Envelope at 50\% Span Across Incidence Set Points 


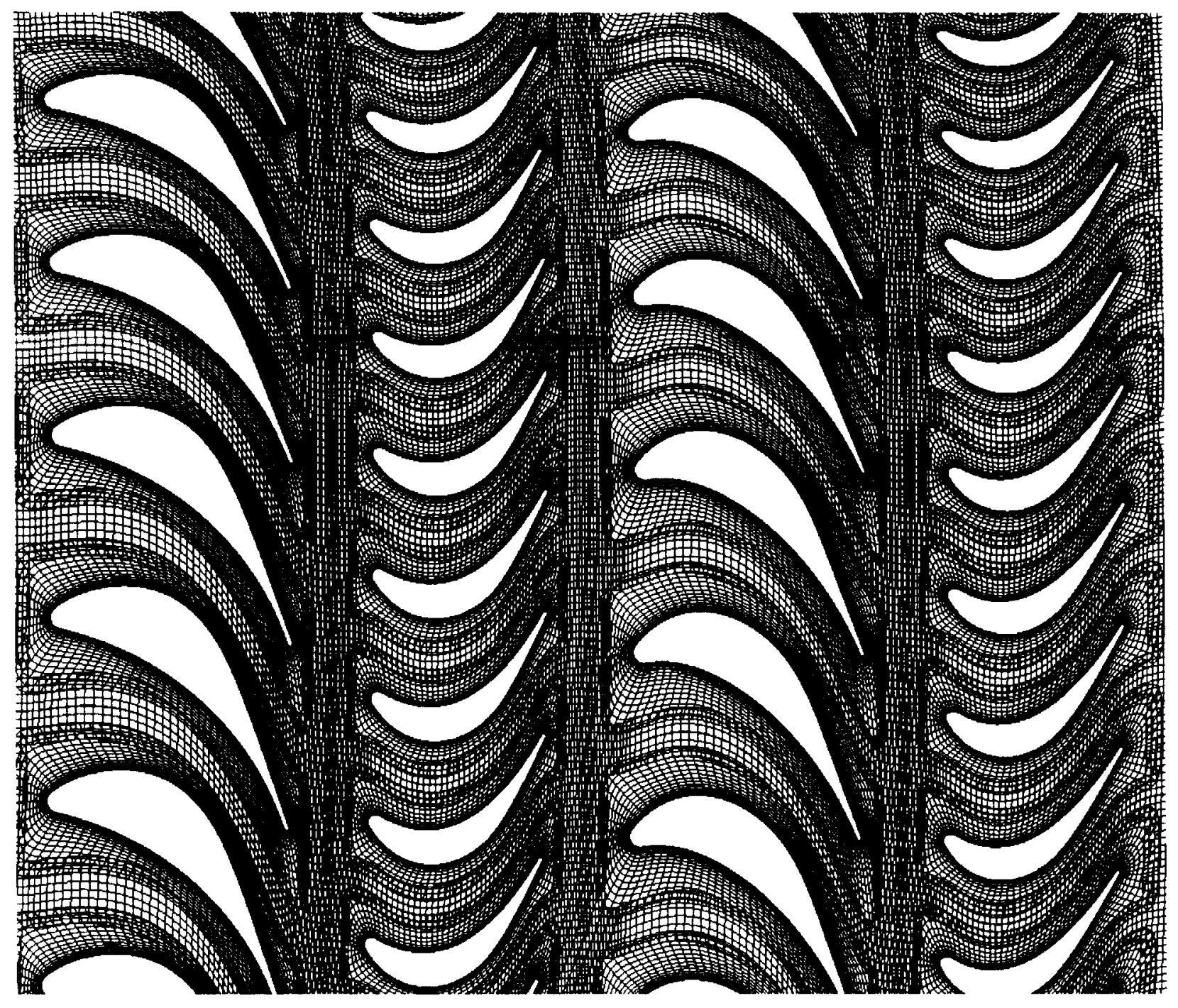

Fig. 11. Mid-span Computational Grid 


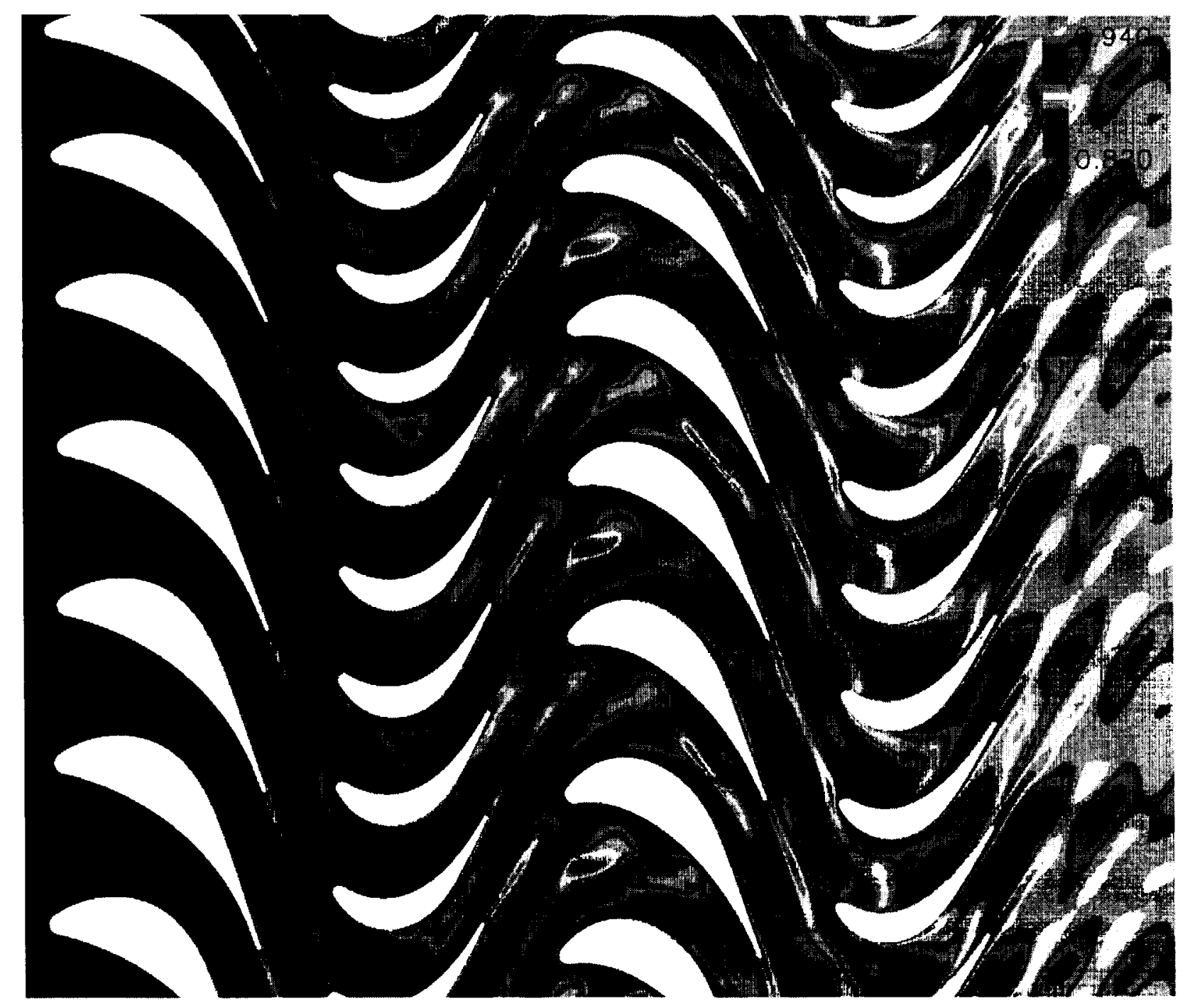

Fig. 12. Mid-span Instantaneous Entropy Contours at the Design Flow Conditions 


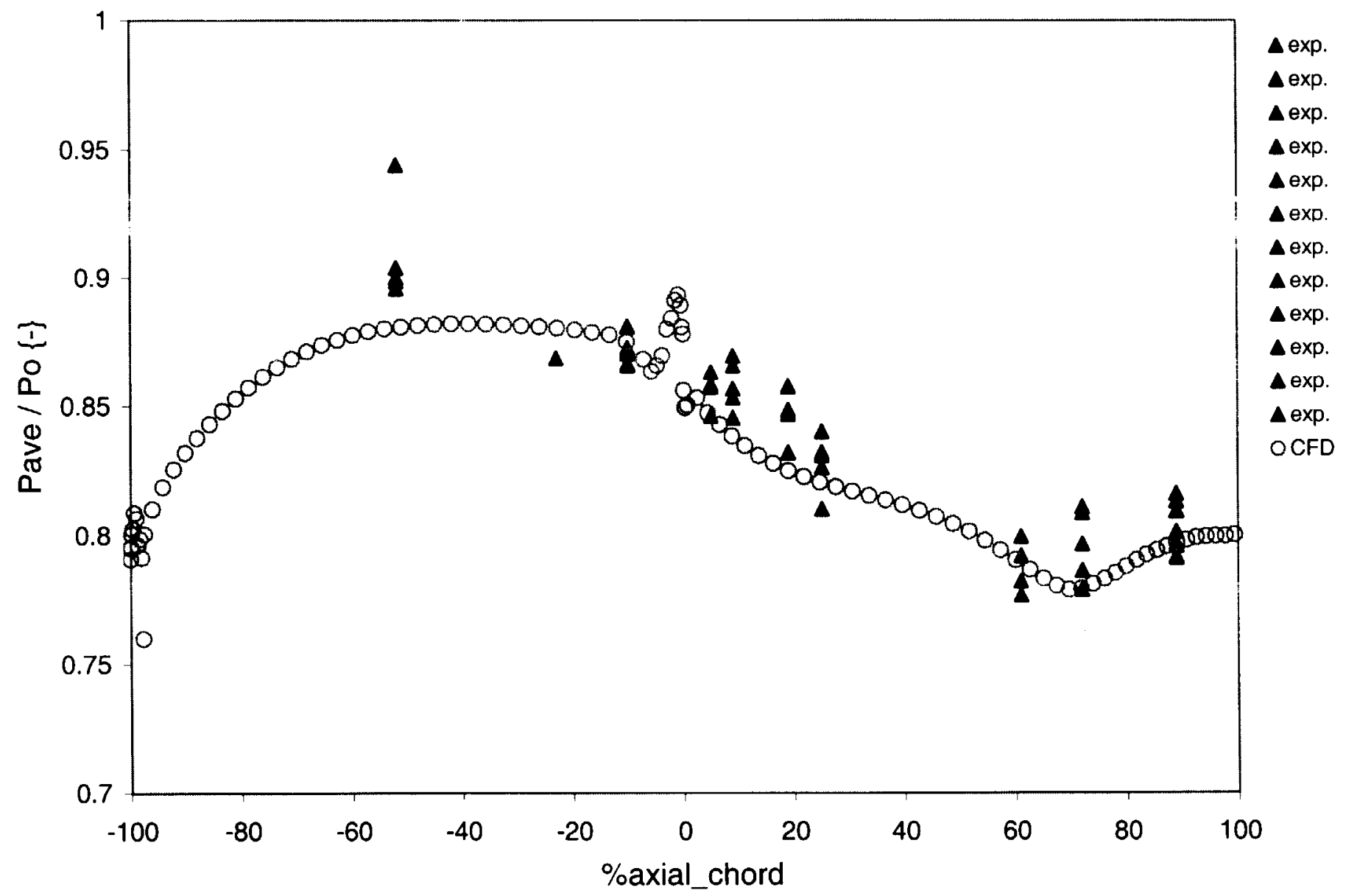

Fig. 13. Time-averaged Surface Pressure at 50\% Span versus CFD Prediction-Design Flow 


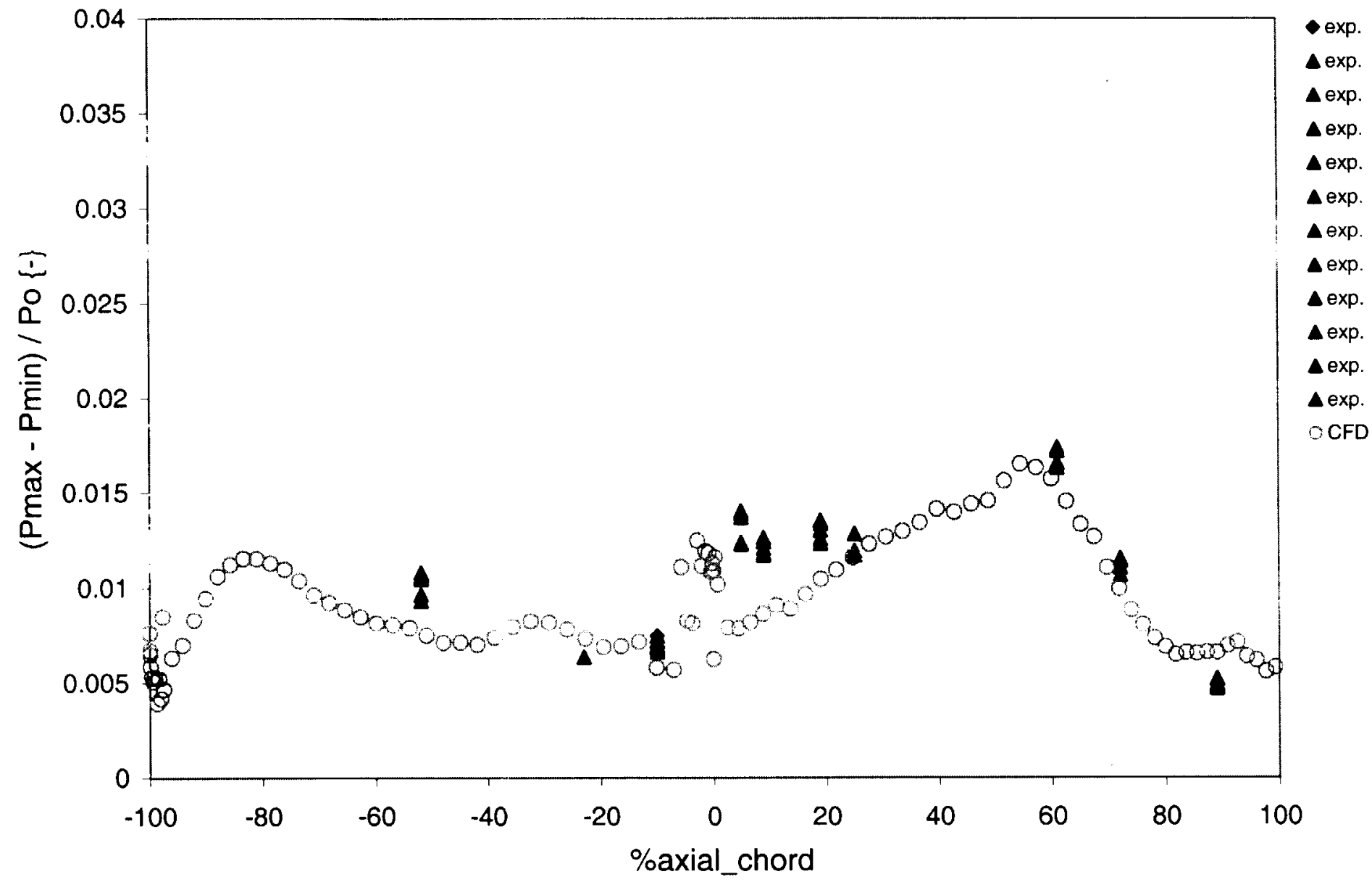

Fig. 14. Unsteady Envelope Pressure at 50\% Span versus CFD Prediction-Design Flow 


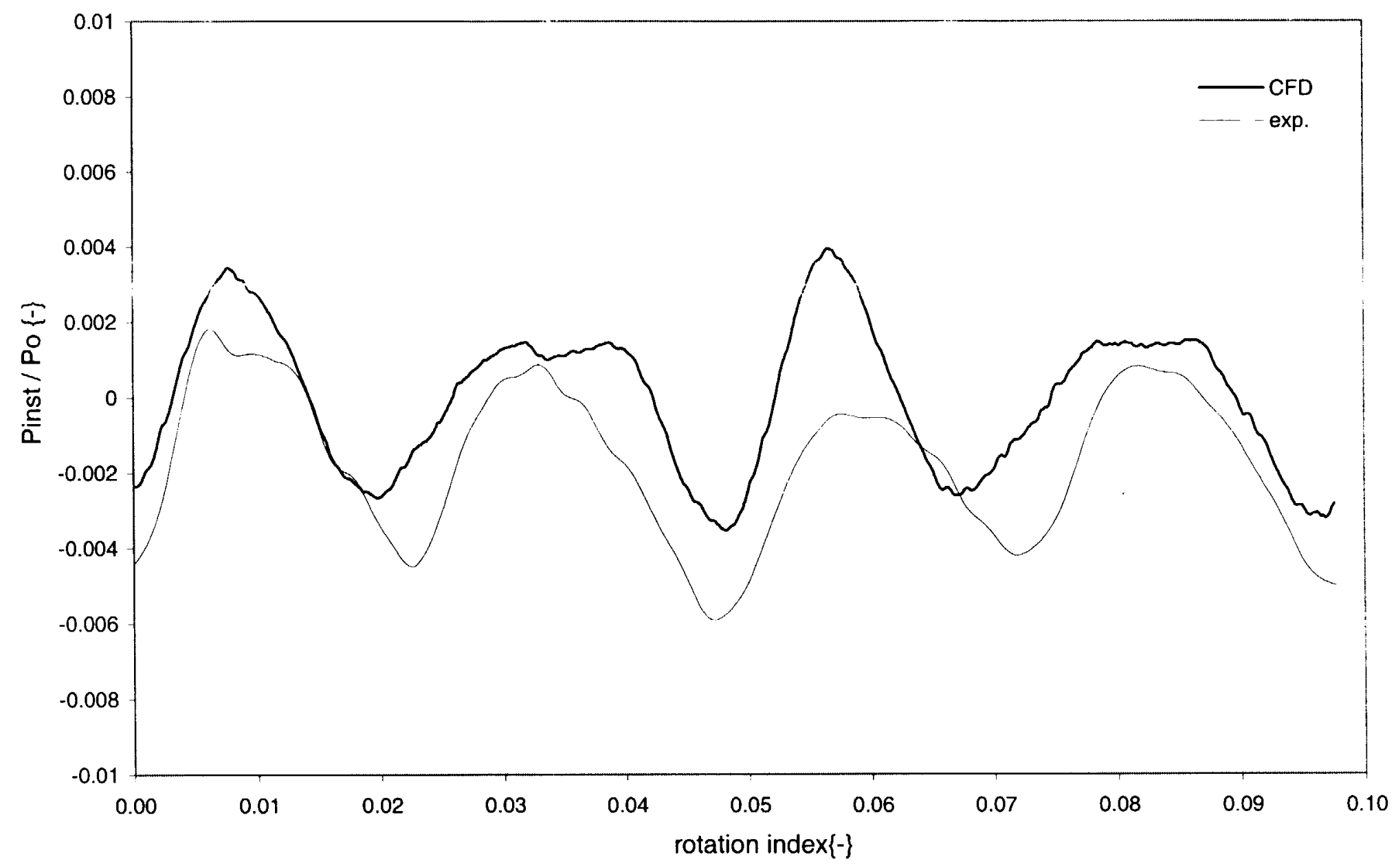

Fig. 15. Instantaneous Pressure Comparison at 50\% Span/Pressure Side—Design Flow 


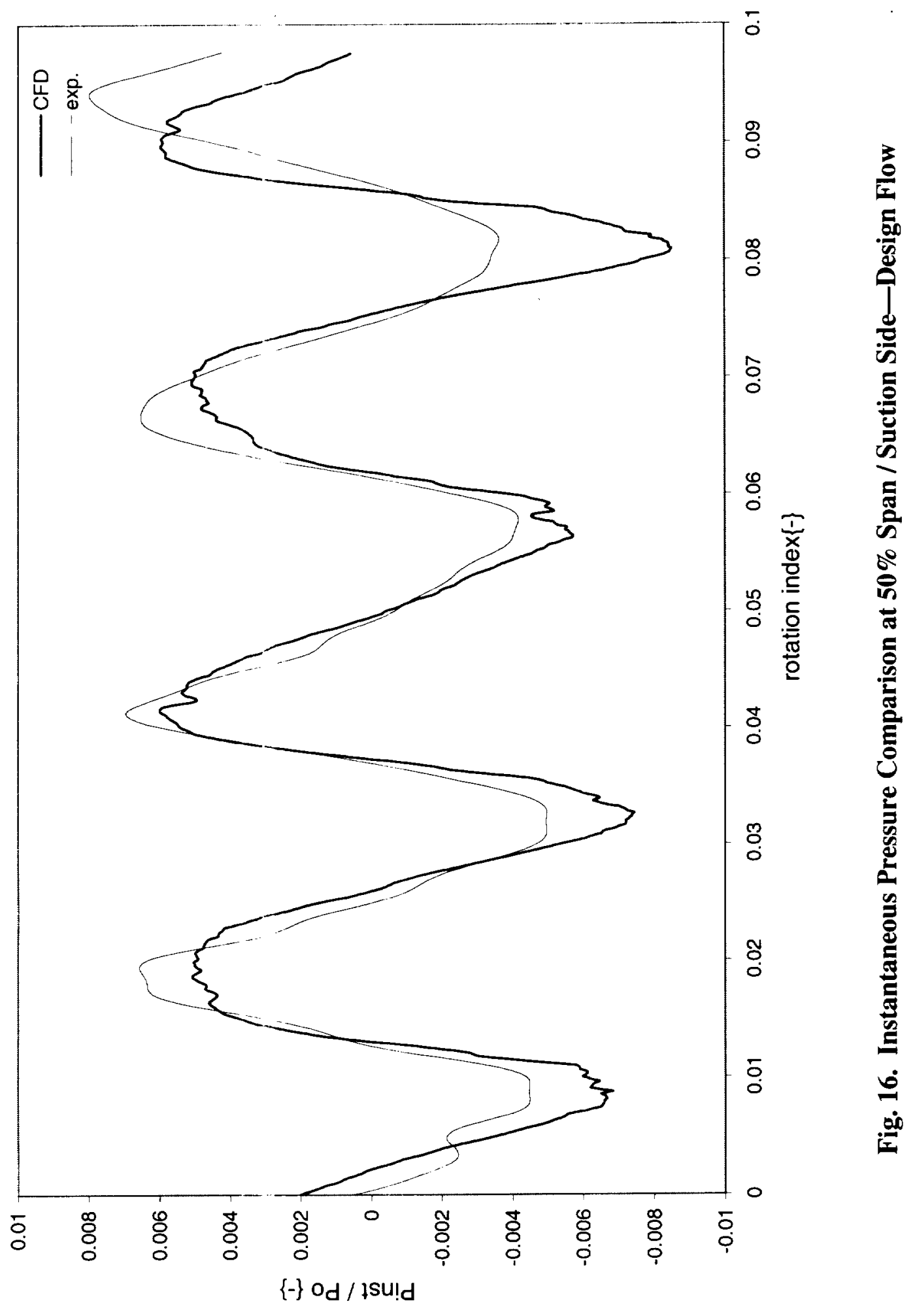

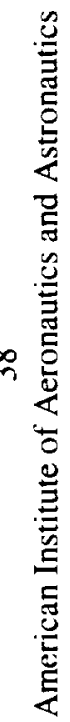




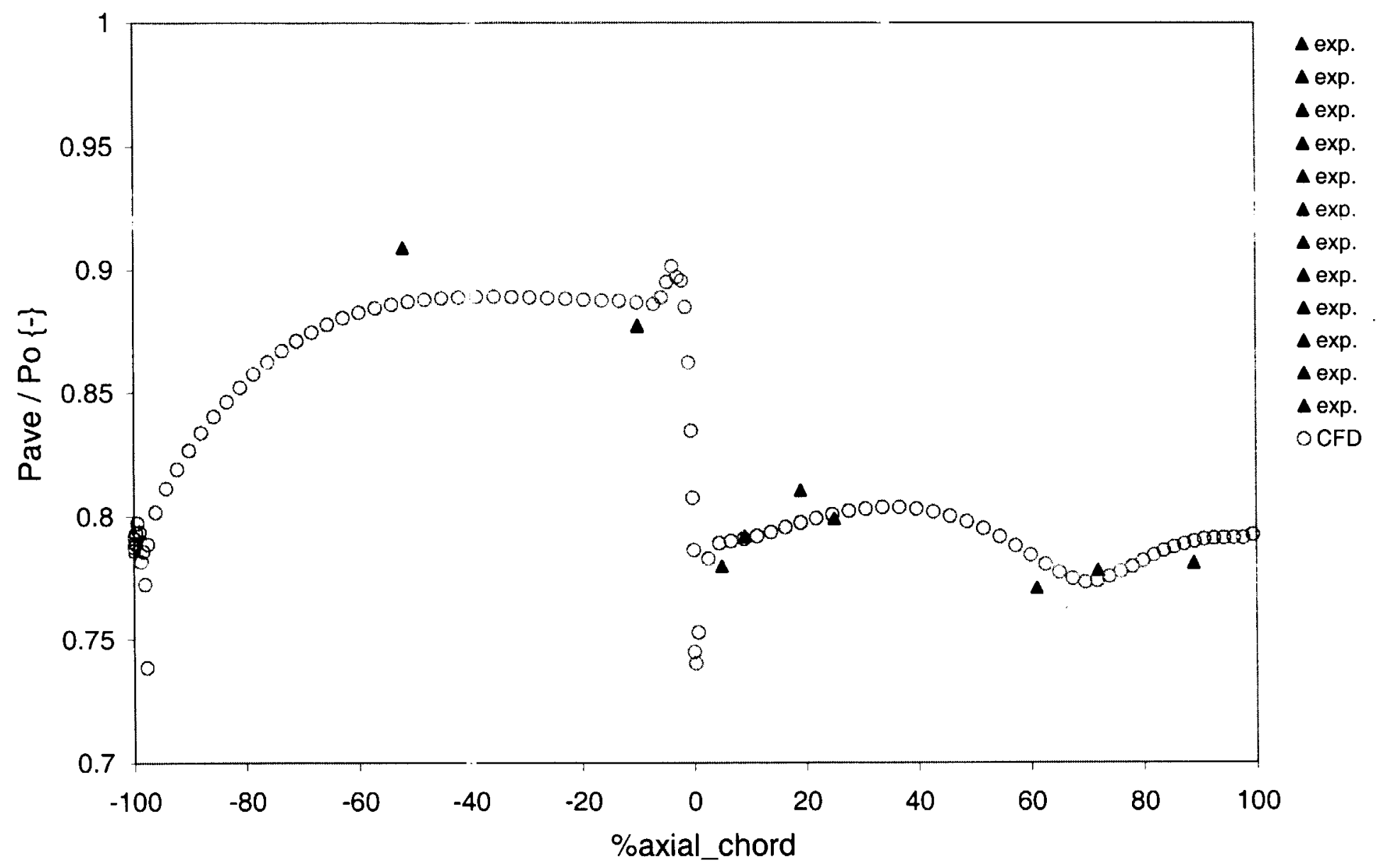

Fig. 17. Average Surface Pressure at 50\% Span versus CFD Prediction at Off-Design 


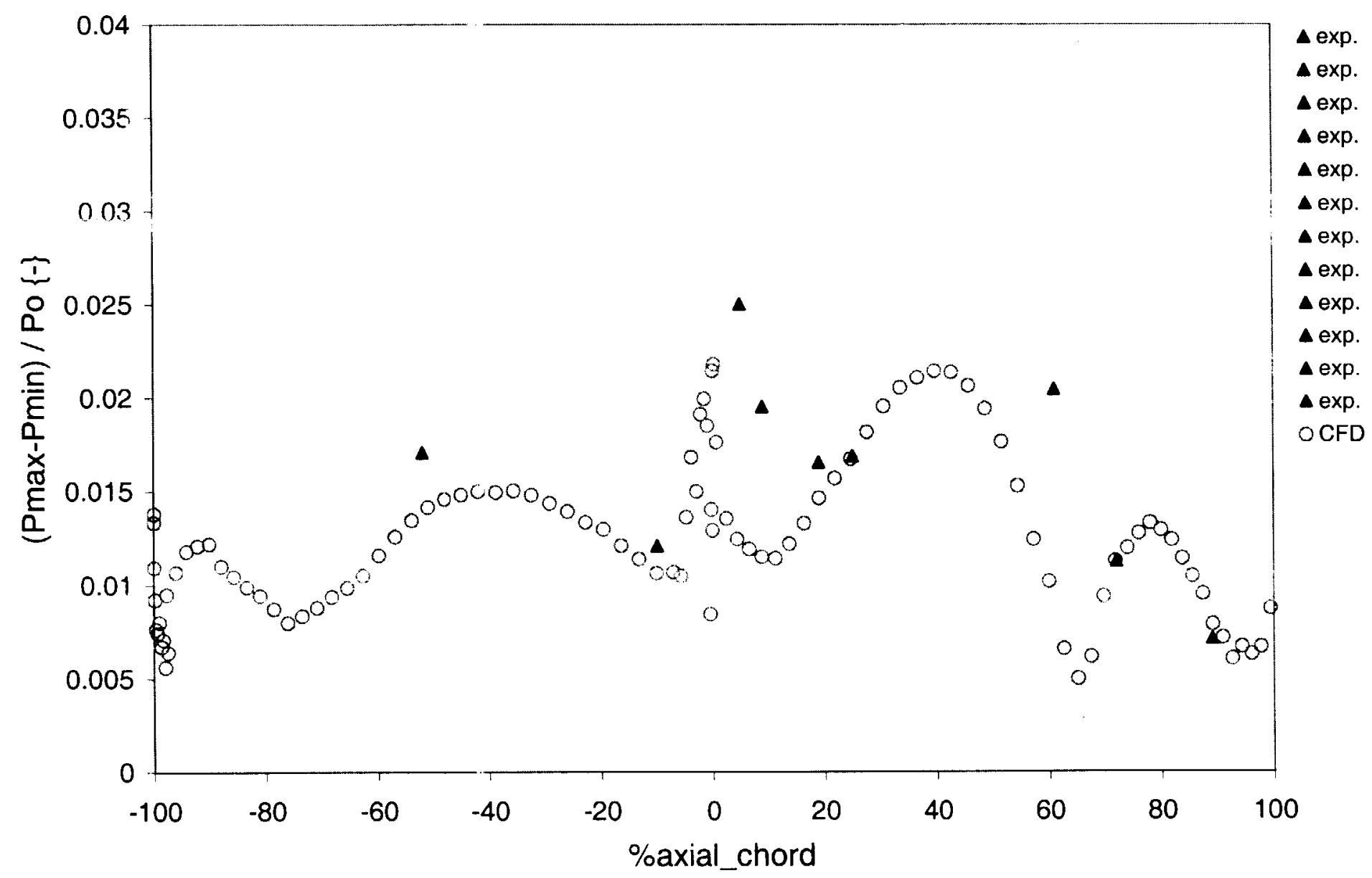

Fig. 18. Unsteady Envelope Pressure at 50\% Span versus CFD Prediction at Off-Design 


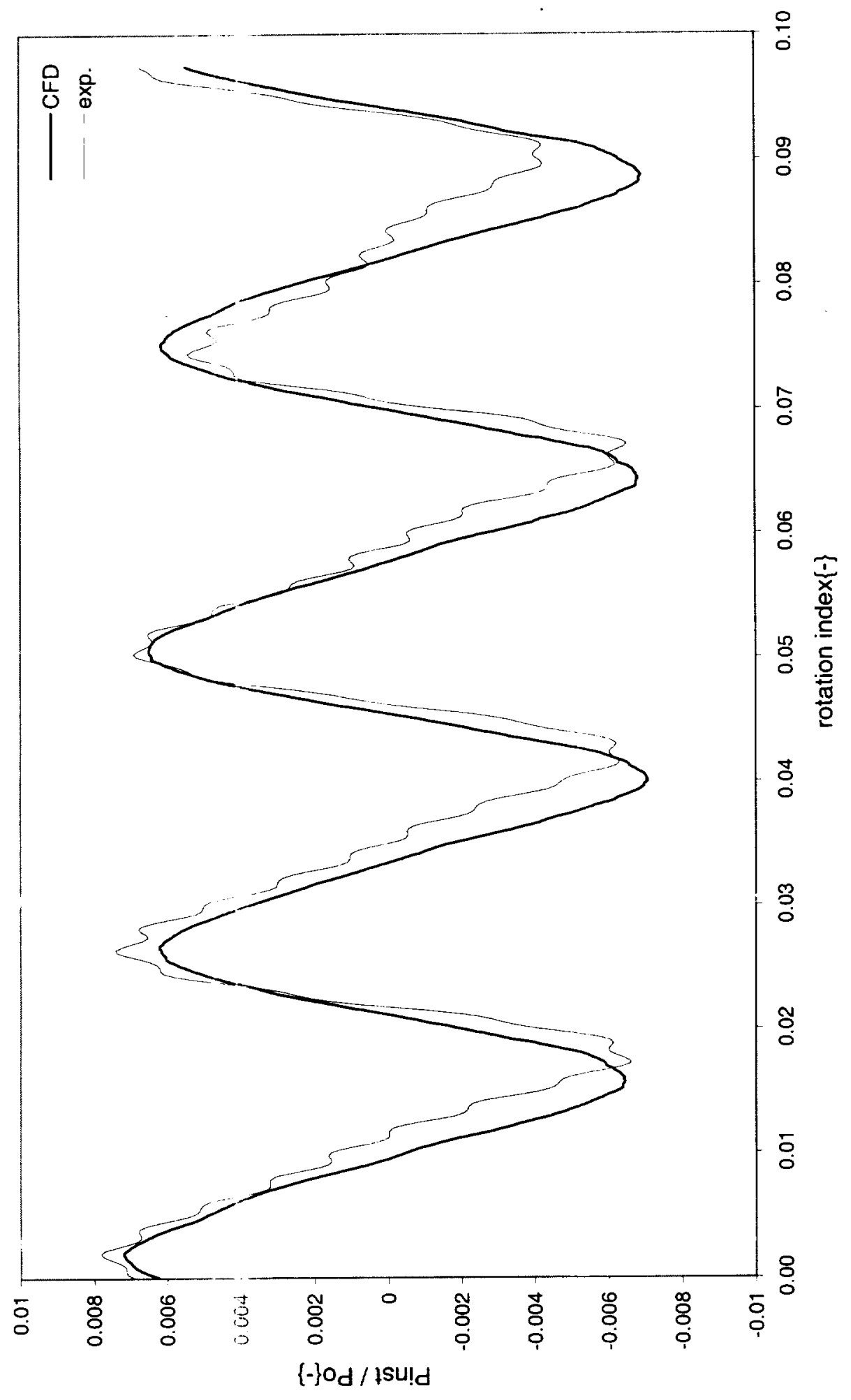

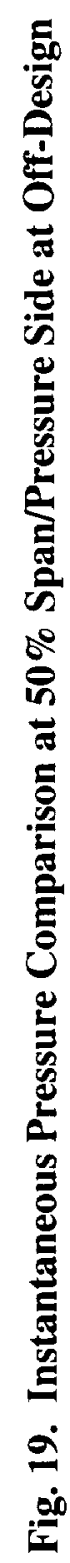

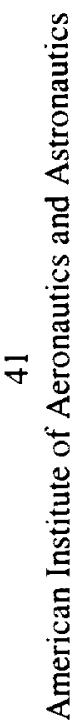




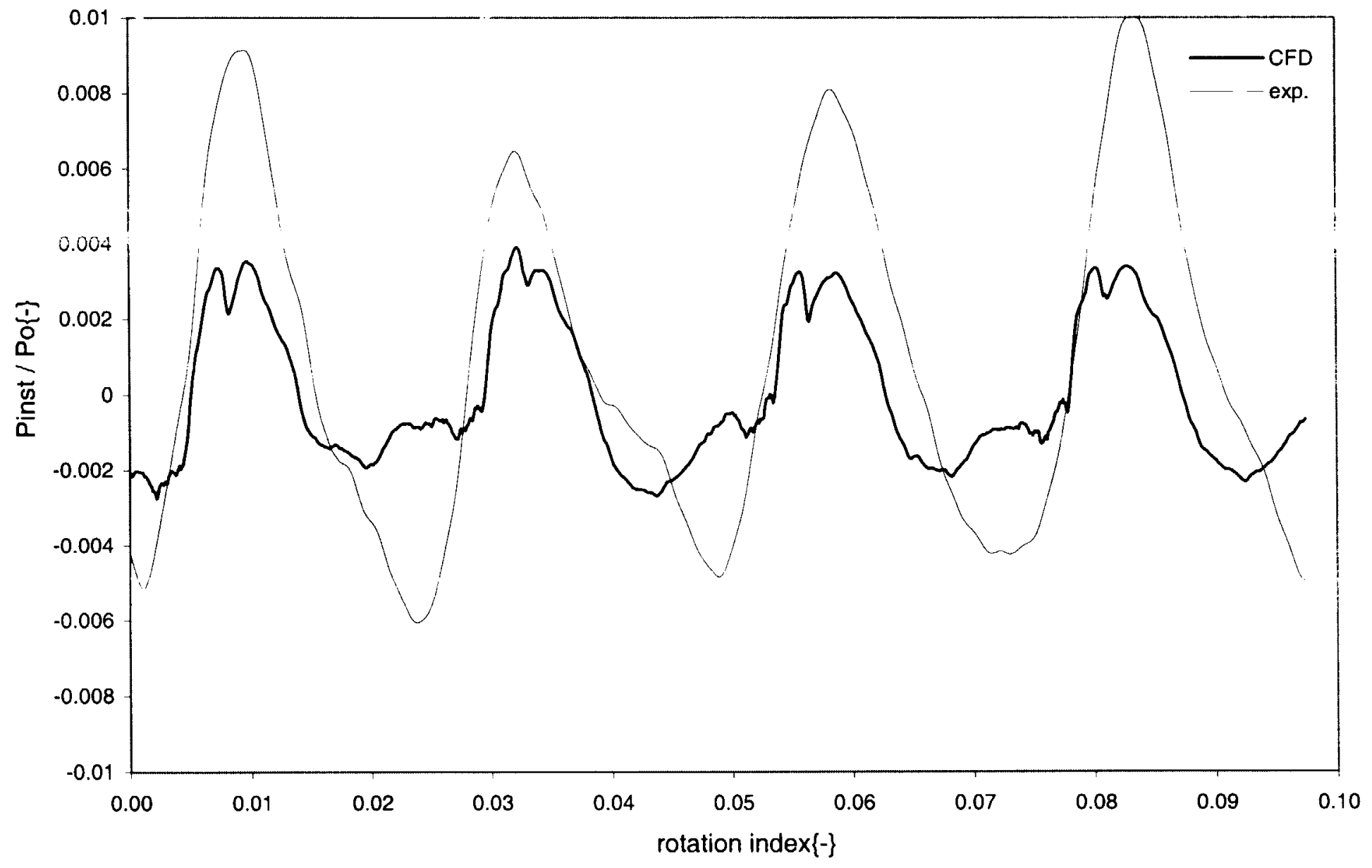

Fig. 20. Instantaneous Pressure Comparison at 50\% Span/Suction Side at Off-Design 
Table 1. Steady State Instrumentation Overview

\section{Turbine Inlet and Exit:}

4 total pressure rakes ( 4 probes each at inlet and 5 probes each at exit).

4 total temperature rakes ( 4 probes each at inlet and 5 probes each at exit).

2 auto-nulling cobra probes with radial actuators.

Automatic circumferential traverse.

\section{Turbine:}

8 inner and 8 outer wall static pressures at 6 axial planes.

Stator surface static pressure's- 6 on pressure side and 8 on suction side at $10 \%$ span, $50 \%$ span, and $90 \%$ span on both stages.

14 stator outer shroud and 11 stator inner shroud static pressures on both stages.

Disk cavity static pressures.

Disk cavity total temperatures.

\section{Exit Guide Vanes:}

12 inner and 12 outer wall static pressures at 2 axial planes.

4 total pressure measurements on 6 vanes.

4 total temperature measurements on 6 vanes.

\section{Miscellaneous:}

2 speed pick-ups.

Accelerometers -2 horizontal, 2 vertical.

Contoured blank plugs for all bosses.

Health monitoring instrumentation. 
Table 2. On-Blade Instrumentation Locations

\begin{tabular}{|c|c|c|c|c|}
\hline $\begin{array}{c}\text { Blade } \\
\#\end{array}$ & \% Span & \% Axial Chord & \% Wetted Length & $\begin{array}{c}\text { Suction/ } \\
\text { Pressure }\end{array}$ \\
\hline 21 & & 14 & 12.5 & $\mathrm{P}$ \\
21 & 90 & 58 & 47.6 & $\mathrm{P}$ \\
21 & 90 & 75 & 65.5 & $\mathrm{P}$ \\
22 & 90 & 7 & 8.5 & $\mathrm{~S}$ \\
22 & 90 & 22 & 19.1 & $\mathrm{~S}$ \\
22 & 90 & 88 & 81.3 & $\mathrm{~S}$ \\
42 & 90 & 13 & 12.0 & $\mathrm{P}$ \\
42 & 10 & 59 & 49.6 & $\mathrm{P}$ \\
42 & 10 & 77 & 66.2 & $\mathrm{P}$ \\
43 & 10 & 5 & 8.3 & $\mathrm{~S}$ \\
43 & 10 & 18 & 20.0 & $\mathrm{~S}$ \\
43 & 10 & 60 & 51.0 & $\mathrm{~S}$ \\
43 & 10 & 83 & 74.7 & $\mathrm{~S}$ \\
63 & 10 & 10 & 9.4 & $\mathrm{P}$ \\
63 & 50 & 23 & 20.3 & $\mathrm{P}$ \\
63 & 50 & 52 & 44.1 & $\mathrm{P}$ \\
63 & 50 & 82 & 75.0 & $\mathrm{P}$ \\
1 & 50 & 5 & 7.3 & $\mathrm{~S}$ \\
2 & 50 & 9 & 11.5 & $\mathrm{~S}$ \\
1 & 50 & 19 & 19.0 & $\mathrm{~S}$ \\
2 & 50 & 25 & 24.0 & $\mathrm{~S}$ \\
1 & 50 & 61 & 50.1 & $\mathrm{~S}$ \\
2 & 50 & 72 & 61.9 & $\mathrm{~S}$ \\
1 & 50 & 89 & 83.0 & $\mathrm{~S}$ \\
\hline
\end{tabular}


Table 3. SSME HPFT Test Matrix

\begin{tabular}{|c|c|c|c|c|c|}
\hline Run/Rerun & $P_{01}$ (psia) & $\mathrm{T}_{01}\left({ }^{\circ} \mathrm{R}\right)$ & N (RPM) & Model $\mathbf{P r}_{\mathrm{t}-\mathrm{t}}$ & Description \\
\hline $8 / 0$ & 100 & 550 & 6982 & 1.47 & Old Design Point \\
\hline $8 / 1$ & 100 & 550 & 6982 & 1.47 & Old Design Point \\
\hline $8 / 2$ & 100 & 550 & 6982 & 1.47 & Old Design Point \\
\hline $9 / 0$ & 50 & 550 & 6747 & 1.61 & Calspan Set Point \\
\hline $9 / 1$ & 50 & 550 & 6747 & 1.61 & Calspan Set Point \\
\hline $8 / 3$ & 100 & 550 & 6982 & 1.47 & Old Design Point \\
\hline $11 / 0$ & 100 & 550 & 6791 & 1.51 & 97 PB_104\%RPL \\
\hline $12 / 0$ & 100 & 550 & 6979 & 1.52 & $97 \mathrm{~PB} \_109 \% \mathrm{RPL}$ \\
\hline $13 / 0$ & 100 & 550 & 5435 & 1.38 & 97 PB_65\%RPL \\
\hline $14 / 0$ & 100 & 550 & 5619 & 1.40 & 97 PB_70\%RPL \\
\hline $15 / 0$ & 100 & 550 & 5970 & 1.43 & 97 PB_80\%RPL \\
\hline $16 / 0$ & 100 & 550 & 6306 & 1.46 & 97 PB_90\%RPL \\
\hline $17 / 0$ & 100 & 550 & 6649 & 1.49 & $97 \mathrm{~PB} \_100 \% \mathrm{RPL}$ \\
\hline $18 / 0$ & 100 & 550 & 2344 & 1.51 & $+25 \mathrm{deg}$ incidence \\
\hline $19 / 0$ & 100 & 550 & 8845 & 1.51 & $-25 \mathrm{deg}$ incidence \\
\hline $20 / 0$ & 100 & 550 & 4895 & 1.51 & +15 deg incidence \\
\hline $21 / 0$ & 100 & 550 & 8032 & 1.51 & $-15 \mathrm{deg}$ incidence \\
\hline $22 / 1$ & 100 & 550 & 6142 & 1.51 & $+5 \mathrm{deg}$ incidence \\
\hline $23 / 0$ & 100 & 550 & 7182 & 1.51 & -5 deg incidence \\
\hline $24 / 0$ & 100 & 550 & 6728 & 1.51 & 0 deg incidence \\
\hline $25 / 0$ & 100 & 580 & 7951 & 1.84 & High Pr Point \\
\hline $25 / 1$ & 100 & 580 & 7951 & 1.84 & High Pr Point \\
\hline $9 / 2$ & 50 & 550 & 6747 & 1.61 & Calspan Set Point \\
\hline $8 / 4$ & 100 & 550 & 6982 & 1.47 & Old Design Point \\
\hline $9 / 3$ & 50 & 550 & 6747 & 1.61 & Calspan Set Point \\
\hline
\end{tabular}


Table 4. Steady State Performance Results

\begin{tabular}{|c|c|c|c|}
\hline & Previous Test & \multicolumn{2}{|c|}{ Current Test } \\
\hline & ODP & ODP & CSP \\
\hline \multicolumn{4}{|c|}{ Facility Measurements } \\
\hline $\mathrm{P}_{0 \mathrm{Fac}}$ & & 99.90 & 50.26 \\
\hline $\mathrm{T}_{0 \mathrm{Fac}}$ & & 548.00 & 548.16 \\
\hline $\mathrm{N}$ & 7004.45 & 7005.98 & 6763.11 \\
\hline$\dot{\mathrm{W}}$ & 13.98 & 14.37 & 7.73 \\
\hline \multicolumn{4}{|c|}{ Model Conditions } \\
\hline$P_{01}$ & 99.47 & 99.89 & 50.24 \\
\hline$T_{01}$ & 547.64 & 545.71 & 545.90 \\
\hline$P_{1}$ & 99.30 & 99.65 & 50.11 \\
\hline $\mathrm{P}_{02}$ & 67.67 & 67.94 & 31.29 \\
\hline$T_{02}$ & 498.65 & 497.17 & 488.53 \\
\hline $\mathrm{P}_{2}$ & 66.34 & 66.66 & 30.43 \\
\hline \multicolumn{4}{|c|}{ Pressure Ratios } \\
\hline$t-t$ & 1.47 & 1.47 & 1.61 \\
\hline $\mathrm{t}-\mathrm{s}$ & 1.50 & 1.50 & 1.65 \\
\hline \multicolumn{4}{|c|}{ Overall Performance } \\
\hline $\mathrm{U} / \mathrm{C}_{0}$ & 0.37 & 0.37 & 0.33 \\
\hline FP & 3.29 & 3.36 & 3.59 \\
\hline$\eta_{\text {th }}$ & 0.857 & 0.853 & 0.831 \\
\hline
\end{tabular}


Table 5. Uncertainty Estimates of Measured Variables

\begin{tabular}{|l|l|l|l|}
\hline & ODP Random & \multicolumn{1}{|c|}{ CSP Random } & \multicolumn{1}{|c|}{ Systematic } \\
\hline $\mathrm{P}_{0 \mathrm{Fac}}$ & $0.050 \mathrm{psi}$ & $0.017 \mathrm{psi}$ & $0.11 \mathrm{psi}$ \\
\hline $\mathrm{T}_{0 \mathrm{Fac}}$ & $0.10^{\circ} \mathrm{R}$ & $0.27^{\circ} \mathrm{R}$ & $1.0^{\circ} \mathrm{R}$ \\
\hline $\mathrm{N}$ & $1.3 \mathrm{RPM}$ & $1.3 \mathrm{RPM}$ & $1.0 \mathrm{RPM}$ \\
\hline$\dot{\mathrm{W}}$ & $0.0037 \mathrm{~b}_{\mathrm{m}} / \mathrm{s}$ & $0.010 \mathrm{lb} \mathrm{m} / \mathrm{s}$ & $1 \%$ reading \\
\hline $\mathrm{P}_{01}$ & $0.037 \mathrm{psi}$ & $0.018 \mathrm{psi}$ & $0.11 \mathrm{psi}$ \\
\hline $\mathrm{T}_{01}$ & $0.11^{\circ} \mathrm{R}$ & $0.26^{\circ} \mathrm{R}$ & $1.0^{\circ} \mathrm{R}$ \\
\hline $\mathrm{P}_{1}$ & $0.034 \mathrm{psi}$ & $0.021 \mathrm{psi}$ & $0.11 \mathrm{psi}$ \\
\hline $\mathrm{P}_{02}$ & $0.057 \mathrm{psi}$ & $0.044 \mathrm{psi}$ & $0.11 \mathrm{psi}$ \\
\hline $\mathrm{T}_{02}$ & $0.079^{\circ} \mathrm{R}$ & $0.16^{\circ} \mathrm{R}$ & $1.0^{\circ} \mathrm{R}$ \\
\hline $\mathrm{P}_{2}$ & $0.060 \mathrm{psi}$ & $0.042 \mathrm{psi}$ & $0.11 \mathrm{psi}$ \\
\hline
\end{tabular}


Table 6. Randonı Component Uncertainty Estimates of Calculated Values

\begin{tabular}{|l|l|l|}
\hline & \multicolumn{1}{|c|}{ ODP Random } & \multicolumn{1}{|c|}{ CSP Random } \\
\hline $\operatorname{Pr}_{t-1}$ & 0.0011 & 0.0023 \\
\hline $\operatorname{Pr}_{t-s}$ & 0.0012 & 0.0024 \\
\hline$U / C_{t}$ & 0.0004 & 0.0005 \\
\hline $\mathrm{FP}$ & 0.0011 & 0.0078 \\
\hline$\eta_{\mathrm{th}}$ & 0.0009 & 0.0008 \\
\hline
\end{tabular}


Table 7. Predicted Time-Averaged Flow Values and Performance Parameters at Design Conditions

\begin{tabular}{|c|c|c|c|c|}
\hline & Vane-1 & Rotor-1 & Vane-2 & Rotor-2 \\
\hline $\mathrm{M}_{1}$ (abs) & 0.138 & 0.432 & 0.178 & 0.430 \\
\hline $\mathrm{M}_{1}(\mathrm{rel})$ & 0.138 & 0.203 & 0.178 & 0.205 \\
\hline $\mathrm{M}_{2}$ (abs) & 0.432 & 0.178 & 0.430 & 0.179 \\
\hline $\mathrm{M}_{2}(\mathrm{rel})$ & 0.432 & 0.367 & 0.430 & 0.355 \\
\hline$P_{1}$ (abs) psia & 98.68 & 86.87 & 80.44 & 81.29 \\
\hline $\mathrm{P}_{2}$ (abs) psia & 86.87 & 80.44 & 81.29 & 66.67 \\
\hline $\mathrm{P}_{01}$ (abs) psia & 100.0 & 98.88 & 82.28 & 81.29 \\
\hline$P_{01}($ rel) psia & 100.0 & 89.48 & 82.28 & 73.69 \\
\hline$P_{02}(a b s)$ psia & 98.88 & 82.28 & 81.29 & 68.19 \\
\hline$P_{02}(\mathrm{rel}) \mathrm{psia}$ & 98.88 & 88.40 & 81.29 & 72.79 \\
\hline $\mathrm{T}_{01}(\mathrm{abs}) \mathrm{R}$ & 546.2 & 546.2 & 520.0 & 520.0 \\
\hline $\mathrm{T}_{01}(\mathrm{rel}) \mathrm{R}$ & 546.2 & 530.8 & 520.0 & 505.5 \\
\hline $\mathrm{T}_{02}$ (abs) $\mathrm{R}$ & 546.2 & 520.0 & 520.0 & 495.9 \\
\hline $\mathrm{T}_{02}(\mathrm{rel}) \mathrm{R}$ & 546.2 & 530.8 & 520.0 & 505.3 \\
\hline$\alpha_{1}(\operatorname{deg})$ & 0.000 & -68.72 & 14.56 & -67.13 \\
\hline$\beta_{1}(\operatorname{deg})$ & 0.000 & -37.02 & 14.56 & -32.00 \\
\hline$\alpha_{2}(\operatorname{deg})$ & 68.72 & 14.56 & -67.13 & 6.70 \\
\hline$\beta_{2}(\operatorname{deg})$ & 68.72 & 62.86 & -67.13 & 60.16 \\
\hline$\dot{\mathrm{W}}\left(\mathrm{lb}_{\mathrm{m}} / \mathrm{sec}\right)$ & 15.2 & 15.2 & 15.1 & 15.1 \\
\hline Power (hp) & -- & 136 & -- & 123 \\
\hline$\eta_{\mathrm{t}-\mathrm{t}(\text { based on } \Delta \mathrm{V})}$ & $-\cdots$ & 0.874 & -- & 0.867 \\
\hline$\eta_{\mathrm{t}-\mathrm{t}(\text { based on } \Delta \mathrm{Tt})}$ & - & 0.884 & -- & 0.887 \\
\hline$\eta_{\mathrm{t}-\mathrm{s}}$ & -- & 0.796 & -- & 0.795 \\
\hline Zwcinfel & .508 & 1.145 & 0.625 & 1.188 \\
\hline
\end{tabular}




\section{Suggested Reviewers:}

Dr. Michael G. Dunn

Professor of Aerospace Engineering

The Ohio State University

Department of Aerospace Engineering and Aviation

2036 Neil Ave., Bolz Hall Room 328

Columbus, $\mathrm{OH}$ 43210-1276.

(614) 292-5015

FAX (614) 292-8290

dunn.129@osu.edu

P. Dean Johnson

Aerodynamics/Project

Florida Turbine Technologies, Inc.

140 Intracoastal Pointe Drive, Suite 211

Jupiter, FL 33477

(561) 746-3317, ext. 261

djohnson@fttinc.com

Dr. Charles Cross

Air Force Research Lab

AFRL/PRTC

1950 Fifth St.

Wright-Patterson AFB, $\mathrm{OH}$ 45433-7251

(937) 656-5530

FAX (937) 986-5532

charles.cross@wpafb.af.mi

Dr. Mitch Wolff

Associate Professor

Department of Mechanical lingineering

123 Russ Center

Wright State University

Dayton, $\mathrm{OH} 45435$

(937) 775-5141

FAX (937) 775-5009

mitch.wolff@wright.edu

Roland J. Szabo

Rocketdyne Propulsion and Power

The Boeing Company

6633 Canoga Ave

Canoga Park, CA 91309

(818) 586-3280

FAX (818) 586-0588

roland.j.szabo@boeing.con 